\title{
Development of Bonding Models Based on the Periodic Table
}

\author{
D. Michael P. Mingos*
}

\begin{abstract}
Kossel and Lewis' description of the chemical bonding in ionic and covalent compounds in 1916 made an important contribution, which connected the Periodic Table to modern valence theory. In a 1919 paper Langmuir made the perceptive observation that neutral molecules, which had the same number of electrons, e.g. $\mathrm{N}_{2}$ and $\mathrm{CO}$ and $\mathrm{N}_{2} \mathrm{O}$ and $\mathrm{CO}_{2}$, had remarkably similar physico-chemical properties. Inorganic chemists have used this isoelectronic principle to interconnect a wide range of compounds and thereby explore the implications of the Periodic Table.
\end{abstract}

Keywords: Isoelectronic · Isostructural · Periodic Table

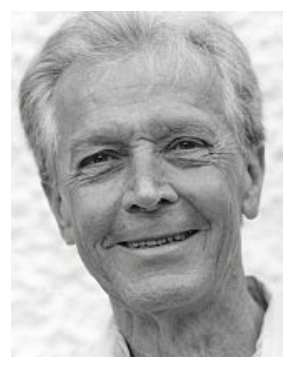

Michael Mingos was born in Basra, Iraq in 1944 and was educated at Harvey Grammar School, Folkestone, King Edward VII School, Lytham St Anne's, University of Manchester and University of Sussex. He has followed a peripatetic academic career in chemistry - Lecturer at Queen Mary College (London), Lecturer and Reader at the University of Oxford (Keble College), Sir Edward Frankland BP Professor and Dean at Imperial College London and Principal of St Edmund Hall Oxford (1999-2009). He was elected to the Royal Society in 1992 and the European Academy of Sciences in 2017. He has received numerous prizes and most recently the Blaise Pascal Medal of the European Academy of Sciences. He holds Honorary Doctorates from the UMIST and Sussex. He is currently an Emeritus Professor at the University of Oxford.

\section{Introduction}

The Periodic Table represents one of the most fruitful and enduring unifying theories in modern science, comparable perhaps with Darwin's theory of evolution. The Periodic Table was not overturned by revolutionary developments in quantum physics in the early $20^{\text {th }}$ century. Kossel and Lewis' papers in 1916 , which connected the valence regularities associated with Mendeleev's Periodic Table to an accessible bonding model, proposed that chemical bonding depended on the attainment of inert gas configurations, either by electron transfer or electron pair sharing. This rather naive model greatly facilitated the acceptance of the quantum mechanical descriptions of the chemical bond, which emerged in the 1920s, and it still forms the backbone of freshman chemistry teaching. The quantitative conclusions of increasingly sophisticated quantum mechanical calculations have been used to underpin the Kossel and Lewis bonding ideas and have provided a way of thinking, which helped inorganic chemists appreciate the richness and complexity of the subject and extend its boundaries. ${ }^{[1,2]}$ The application of quantum mechanical equations and modern computer technology has resulted in readily available computer programmes which may be used to accurately calculate

${ }^{\star}$ Correspondence: Prof. Dr. D. M. P. Mingos

E-mail: michael.mingos@seh.ox.ac.uk

Inorganic Chemistry Laboratory, University of Oxford, South Parks Road, Oxford OX1 3QR, UK specific physical properties of known compounds. However, the synthesis of new groups of compounds still depends heavily on a creative process which starts with conceptual generalisations derived from the Periodic Table and the Kossel and Lewis model. Chemistry has retained a distinctive character, and its practitioners bring together modern theoretical ideas with empirical generalisations to develop strategies for making new molecules, which display either important structural features or interesting chemical or physical properties.

In its initial form the Periodic Table organised the elements on the basis of their atomic weights and showed that if the data were presented in a tabular form then certain trends in the physical and chemical properties of the elements became apparent. Its success lay not only in giving the subject a structure, but it also led to the prediction of new elements, which were highlighted by gaps in the Table. Interpolations of the physical and chemical properties of adjacent known elements resulted in reasonably accurate estimates of their properties and helped chemists identify minerals, where they may be found and subsequently separated and purified using procedures developed for elements in the same group. As the Periodic Table mapped the basic geography of the chemical elements in the late $19^{\text {th }}$ Century, the attention of chemists moved increasingly towards the study of the millions of compounds which could result from the reactions of the elements. The Periodic Table, since it contained information concerning the dominant and subsidiary valencies of each element, provided important signposts for these explorations. The idea that elements had specific valencies can be traced back to Williamson, Odling, Kolbe, Frankland, Couper and Kekule and the tetravalent nature of carbon played a very important role in the development of organic chemistry in the latter half of the $19^{\text {th }}$ Century. ${ }^{[3]}$ Mendeleev was reluctant to use valency as a primary criterion for the development of the Periodic law, because it did not provide a unique parameter for each element, but nonetheless he recognised its importance in defining the chemical inclinations of an element. The majority of inorganic textbooks still use the Periodic Table for organising the exponentially growing number of new compounds, although additional sections are added to cover special topics such as bioinorganic chemistry, organometallic chemistry, solid state chemistry and materials. ${ }^{[4-14]}$

Dimitri Mendeleev, Julius Lothar Meyer and others developed the Periodic law and its graphical representation as a Table before the electron had been discovered. Experiments by Rutherford led to the description of the atom as composed of small electrons circulating a positively charged massive nucleus containing protons 
and neutrons. ${ }^{[1]}$ These days the practical benefit of the Periodic Table for an inorganic chemist lies in its pictorial representation of the known elements organised on the basis of their atomic numbers in a tabular form. It triggers in the mind of a chemist a collection of qualitative generalisations, which help him/her remember key facts regarding the structural, physical and chemical properties of compounds of that element and inter-relate them to other elements in neighbouring parts of the Periodic Table. The modern Periodic Table also defines regions which have characteristic types of elements. The descriptions metal, non-metal, alkali and alkaline earth metals, transition metals, lanthanides and actinides, noble and coinage metals, chalcogenides, halogens and noble gases are evocative in the same way as a redolent smell generates a cascade of memories and inter-connections. ${ }^{[12]}$

The modern chemist does not attempt to memorise the detailed properties of the 118 officially recognised elements and their millions of compounds, but is guided by the Periodic Table towards the formulae of typical compounds for each of the main groups of the Periodic Table, the characteristic valencies of the element, the types of bonds to other elements it may form and certain generalisations based on the total number of valence electrons in their molecules. The modern structure of the Periodic Table is therefore intimately connected to the atomic structures of atoms and the concepts of valency, which arise from this description, and more specifically to the number and types of bonds formed by groups of elements. The generally accepted form of the Periodic Table has been underpinned by the emergence of a quantum mechanical wave description of the electronic structures of atoms and molecules. This review traces the interplay between the Periodic Table and valence theory and in particular the importance of isoelectronic relationships.

\section{Isoelectronic Relationships in Ionic Compounds}

Lewis and Kossel simultaneously recognised that the valencies of the lighter elements were intimately connected with the formation of octets of electrons. ${ }^{[15-19]}$ In 1916 they independently proposed that chemical compounds could be described in terms of ions formed by the transfer of electrons from one atom to its neighbour and thereby achieve octets which are isoelectronic with the inert gas atoms first discovered by Ramsay and Rayleigh around $1900 . .^{[20]}$ For example, $\mathrm{KCl}$ could be described in terms of the formation of the ions $\mathrm{K}^{+}$and $\mathrm{Cl}^{-}$, which both have the same number of electrons as argon, the inert gas located between $\mathrm{K}$ and $\mathrm{Cl}$ in the Periodic Table. The attractive forces between the oppositely charged ions provided an electrostatic explanation for the occurrence and stability of these ionic bonds. Lewis's 1916 article titled 'The Atom and the Molecule' proved to be one of the most influential works in modern chemistry since it also proposed a second type of chemical bond - the covalent bond - for those molecular compounds, whose solubility and physical properties were not compatible with the presence of separated ions. ${ }^{[15]}$ Lewis attributed the stability of the covalent bond to the sharing of pairs of electrons between atoms so that each atom effectively achieves an inert gas electron configuration by co-operatively sharing electron pairs rather than by electron transfer. For example, $\mathrm{CF}_{4}$ has four covalent $\mathrm{C}: \mathrm{F}$ bonds formed by the sharing of pairs of electrons between carbon and fluorine and both atoms thereby achieve the octet of valence electrons associated with the neon atom. Lewis recognised that the covalent and ionic chemical bond descriptions represented two extremes of a continuum of bonds with increasing polarities. As the abilities of the atoms to attract electrons increases, i.e. in modern parlance as the electronegativity difference between the atoms becomes larger, the bonds become progressively less covalent and more ionic.[17]

The Lewis-Kossel description of the ionic bond incorporated two key concepts which have remained central to chemical thinking ever since. Firstly, the formation of ions with inert gas config- urations results in an isoelectronic series. For example, the ions $\mathrm{Al}^{3+}, \mathrm{Mg}^{2+}, \mathrm{Na}^{+}: \mathrm{F}^{-}, \mathrm{O}^{2-}$, and $\mathrm{N}^{3-}$ are all isoelectronic with the neutral and independently stable inert gas atom Ne. ${ }^{[15,18]}$ Therefore, $\mathrm{NaF}, \mathrm{MgO}$ and $\mathrm{AlN}$ have the same cation to anion ratio and have isoelectronic constituent ions. The differently charged ions may also combine to form compounds with alternative stoichiometries which are electroneutral, e.g. $\mathrm{MgF}_{2}, \mathrm{AlF}_{3}, \mathrm{Na}_{2} \mathrm{O}, \mathrm{Al}_{2} \mathrm{O}_{3}$, etc. The contemporaneous development of X-ray crystallography enabled structural chemists to establish that all these ionic compounds had infinite structures rather than separate $\mathrm{Na}^{+} \mathrm{F}^{-}$and $\mathrm{Mg}^{2+} \mathrm{O}^{2-}$ entities. Indeed $\mathrm{NaF}$ and $\mathrm{MgO}$ are isostructural and the cations and anions have 3-dimensionally linked octahedral co-ordination geometries. The isomorphous cubic cells have the dimensions 4.64 and 4.21 $\AA$ respectively. AlN also has an infinite structure but the cations and anions have tetrahedral co-ordination geometries based on the Wurtzite structure which is hexagonally close packed and has cell dimensions $\mathrm{a}=\mathrm{b}=3.11$ and $\mathrm{c}=4.98 \AA .{ }^{[21]}$ The important point to note is that ionic isoelectronic compounds with the same formula are frequently, but not always isostructural. As the charges on the constituent ions become larger the bonding becomes more covalent and directional covalent bonds assume a greater significance than the electrostatic bonds. The change from octahedral to tetrahedral signals these directional covalent bonding effects. ${ }^{[11]}$

Secondly, Lewis and Kossel recognised that the regular chemical relationships associated with columns of the Periodic Table had its origins in the atoms having common numbers of valence active electrons outside a central core of inner (core) electrons, which do not participate greatly in chemical bonding. The latter do not participate in the formation of ionic or covalent bonds, because they experience strong electrostatic interactions with the positively charged nucleus. The former participate in ionic and covalent bonds by the transfer or sharing of electrons. For example, the series of compounds $\mathrm{LiF}, \mathrm{NaF}, \mathrm{KF}, \mathrm{CsF}$ and $\mathrm{RbF}$ and $\mathrm{KF}, \mathrm{KCl}, \mathrm{KBr}$ and $\mathrm{KI}$ share common formulae and structural characteristics because the metal ions and the halide anions have common numbers of valence electrons (i.e. 1 for the alkali metals and 7 for the halides). In these specific examples, the series $\mathrm{LiF}-\mathrm{RbF}$ and $\mathrm{KF}-\mathrm{KI}$ all share the $\mathrm{NaCl}$ structure. The electron transfer leads to ionic bonding and results in cations and anions with inert gas configurations, but not the same inert gas in each case. So they are not strictly isoelectronic, but they are valence isoelectronic. ${ }^{[13,19]}$ The series of compounds listed in Table 1 are isomorphous and isostructural and adopt infinite structures based on arrays of linked tetrahedra, i.e. the zinc blende sphalerite structure. The structures are based on that observed in elemental silicon and germanium. ${ }^{[21]}$

Table 1. Isomorphous and isoelectronic Group 13 and 15 binary compounds and their cubic lattice parameter (a).

$$
\begin{array}{|c|c|c|c|}
\hline \mathrm{BN}(3.6 \AA) & & & \\
\hline \mathrm{BP}(4.5 \AA) & \mathrm{AlP}(5.5 \AA) & \mathrm{GaP}(5.5 \AA) & \mathrm{InP}(5.9 \AA) \\
\hline \mathrm{BAs}(4.8 \AA) & \mathrm{AlAs}(5.7 \AA) & \mathrm{GaAs}(5.7 \AA) & \mathrm{InAs}(6.1 \AA) \\
\hline & \mathrm{AlSb}(6.1 \AA) & \mathrm{GaSb}(6.1 \AA) & \mathrm{InSb}(6.5 \AA) \\
\hline
\end{array}
$$

Semiconductors based on $\mathrm{Si}$ and Ge (Group 14 elements) and the isoelectronic compounds, e.g. GaAs, $\mathrm{CdS}$ and $\mathrm{ZnS}$, have played an important role in the development of transistors, silicon chips, photocells etc. Isoelectronic compounds given in Table 1 are achieved either by replacing the Group 14 elements by a pair of Group 13 and 15 elements and $\mathrm{CdS}$ and $\mathrm{ZnS}$ by replacing a pair of Group 14 elements by a Group 12 and 16 element. This mode of substitution provides an important mechanism for fine tuning the electronic band gap in these semiconductors. ${ }^{[21]}$ 
Table 1 summarises the cell dimensions in the related isomorphous and isoelectronic binary semi-conducting compounds. The Lewis-Kossel distinction between core and valence electrons suggests that for elements in the same group the valence electrons occupy successively larger shells as the atomic number increases. ${ }^{[15-19]}$ It follows from this model that the internuclear distance and corresponding cell dimensions should become progressively larger as the column is descended. Table 1 confirms that this is the case for $\mathrm{B} / \mathrm{Al}$ and $\mathrm{Ga} / \mathrm{In}$, but the equal dimensions for the $\mathrm{Al}$ and Ga suggests that this electronic shell description of atoms may be an over-simplification.

The Bohr description of atoms required that the orbits occupied by the electrons in atoms be restricted and defined by a quantum number, $\mathrm{n}$. The wave nature of the electron suggested by diffraction experiments and elucidated by quantum mechanics in the 1920s led an alternative description of atoms based on spherically noded standing waves rather than rotations of particles in well-defined orbits around the nucleus. ${ }^{[3,12]}$ This quantum mechanical wave description of atoms has led to a model, which elegantly accounts for the overall shape of the Periodic Table as we know it today. ${ }^{[1]}$ Quantum mechanics defines the shells occupied by electrons not only by a principal quantum number, $n$, which defines the number of radial nodes associated with each shell, but also introduced for the first time the idea of sub-shells which had non-spherical components. A spherical shell may be inflated like a balloon to produce a larger but still spherical shape and since only the radius has altered the quantum mechanical description of the wave functions are defined by the quantum number $n$, which defines the number of radial nodes. These spherical wave functions are described as s orbitals. Specifically, $1 \mathrm{~s}, 2 \mathrm{~s}, 3 \mathrm{~s}$ and $4 \mathrm{~s}$ orbitals have $0,1,2,3 \ldots(n-1)$ radial nodes and the radius of the spherical surface where the electron density is greatest becomes progressively larger.

Alternatively, a balloon may be distorted by squeezing it using both hands in one plane to produce a non-spherical shape which protrudes above and below the plane defined by the hands. These angular distortions form the basis of the sub-shells in the quantum mechanical description of electrons in atoms. Sub-shell orbitals which are distorted in the way described above are described as $p$ orbitals and there are three equivalent components since the plane formed by the pair of hands can lie in three distinct planes lying $90^{\circ}$ to each other. Although each component is no longer spherical, if all three components are occupied equally by electrons the resultant electron density is spherical. Successive p sub-shells have the following number of radial and angular nodes $-2 p(0$ radial, 1 angular), $3 p$ (1 radial, 1 angular), $4 p$ (2 radial, 1 angular).

In contrast to classical physics the quantum mechanical description allows the energy of the spherical wave function to be increased by introducing either radial or angular nodes. The quantum numbers restrict their energy states in a way reminiscent of the Bohr atom, but with the possibility of having sub-shells. For each sub-shell the total number of radial and angular nodes is $(\mathrm{n}-1)$. The p sub-shells which have one angular node must have a minimum of $n=2$, the $d$ sub-shell, with 2 angular nodes must have a minimum $\mathrm{n}=3$ and $\mathrm{f}$, with 3 angular nodes, must have a minimum $n=4$. Furthermore, the introduction of angular nodes which distort the spherical shape may be achieved in a larger number of independent ways as the number of angular nodes (a) increases (i.e. $2 \mathrm{a}+1$ ). Specifically, the number of distinct but equivalent orbitals in the s, $p, d$ and $f$ sub-shells is $1,3,5$ and 7 respectively. ${ }^{[1,12]}$

In summary, the quantum mechanical description of the atom represents the electrons in an atom in terms of wavefunctions, whose energies are restricted by radial and angular nodes, defined by integer quantum numbers. This leads to a sub-shell structure for the atom and a Periodic Table based on blocks of elements with different dimensions which depend on the number of angular nodes in the wavefunctions.
The quantum mechanical analysis described above defines a shell structure for atoms but unless it also provides a method of defining the number of electrons which may be inserted into each orbital in a sub-shell then it is no more useful to a chemist than an IKEA bookcase without the accompanying instructions. The Pauli Exclusion Principle provided the requisite and rigorous defining rule for the quantum world. It may be taken as a given that the most stable sub-shells are filled first and this is described as the aufbau principle. The Exclusion Principle limits the occupation of each orbital to two electrons with opposite spins. Since the number of angular nodes limits the number of orbitals to 1 for $\mathrm{s}$ orbitals; 3 for $\mathrm{p}$ orbitals, 5 for d orbitals and 7 for $\mathrm{f}$ orbitals they can accommodate up to 2, 6, 10 and 14 electrons. The filled subshells have spherically symmetric electron density. Therefore, the Periodic Table bookcase has shelves which can accommodate only 2, 6, 10 and 14 equal-sized books.

For the hydrogen atom $n s, n p \ldots(n=1,2, \ldots)$ sub-shells have the same energy, for a 1 electron atom the radial nodes lead to equal energies for the sub-shells. If this shell structure was retained in polyelectronic atoms then an aufbau filling of shells would result in completed shells for $2(\mathrm{n}=1) ; 8(\mathrm{n}=2) ; 18(\mathrm{n}=3)$ and 32( $\mathrm{n}=4$ ) electrons, i.e. successive rows of the Periodic Table would have 2, 8, 18 and 32 and 50 elements. In polyelectron atoms the sub-shells no longer have the same energies and the spread in their relative energies leads to a more complex shell structure. The electrons in specific sub-shells are shielded to some extent from the positively charged nucleus by electrons in the more stable inner shells. Moreover, since the electrons are described by a wave function which extends towards the nucleus they partially penetrate the inner shells and experience some attraction from the nucleus. The electrons naturally also experience electron repulsion from other electrons and this results in correlation effects whereby the electrons occupy as far as possible different regions of space to minimize these repulsive effects. This complex situation has been addressed within the quantum mechanical framework and to a first approximation the ns, np nd and nf subshells in poly-electron atoms no longer have the same energy and the orbital filling follows a different general pattern, i.e. $1 \mathrm{~s} ; 2 \mathrm{~s} 2 \mathrm{p} ; 3 \mathrm{~s}$ $3 \mathrm{p} ; 4 \mathrm{~s} 3 \mathrm{~d} 4 \mathrm{p} ; 5 \mathrm{~s} 4 \mathrm{~d} 5 \mathrm{p} ; 6 \mathrm{~s} 4 \mathrm{f} 5 \mathrm{~d} 6 \mathrm{p} ; 7 \mathrm{~s}$ 5f 6d 7p. The principal quantum number $n$ no longer completely dominates the energy spectrum and the $\mathrm{d}$ and $\mathrm{f}$ sub-shells no longer remain associated with the $\mathrm{s}$ and $\mathrm{p}$ sub-shells with the same $\mathrm{n}$ quantum number, e.g. $3 \mathrm{~d}$ becomes associated with $4 \mathrm{~s}$ and $4 \mathrm{p}$ rather than $3 \mathrm{~s}$ and $3 \mathrm{p}$. This results in the less symmetric shape for the Periodic Table shown in Table 2. Each horizontal row finishes with an element which is a noble gas, i.e. the atomic numbers: $2\left(\mathrm{He} ; 1 \mathrm{~s}^{2}\right), 10\left(\mathrm{Ne} ; 1 \mathrm{~s}^{2}, 2 \mathrm{~s}^{2}, 2 \mathrm{p}^{6}\right)$ $18\left(\mathrm{Ar} ; 1 \mathrm{~s}^{2}, 2 \mathrm{~s}^{2}, 2 \mathrm{p}^{6} 3 \mathrm{~s}^{2} 3 \mathrm{p}^{6}\right), 36\left(\mathrm{Kr} ; 1 \mathrm{~s}^{2}, 2 \mathrm{~s}^{2}, 2 \mathrm{p}^{6} 3 \mathrm{~s}^{2} 3 \mathrm{p}^{6} 4 \mathrm{~s}^{2} 3 \mathrm{~d}^{10} 4 \mathrm{p}^{6}\right), 54$ $\left(\mathrm{Xe} ; 1 \mathrm{~s}^{2} \ldots 4 \mathrm{~s}^{2} 3 \mathrm{~d}^{10} 4 \mathrm{p}^{6} 5 \mathrm{~s}^{2} 4 \mathrm{~d}^{10} 5 \mathrm{p}^{6}\right)$ and $86\left(\mathrm{Rn} ; 1 \mathrm{~s}^{2} \ldots . .6 \mathrm{~s}^{2} 4 \mathrm{f}^{14} 5 \mathrm{~d}^{10} 6 \mathrm{~s}^{6}\right)$. The inert nature of these gases arises because their outermost electrons have a high ionization potential, which makes them less available for ionic and covalent bond formation. Also since all their sub-shells are completely filled their total electron density is spherically symmetric. ${ }^{12,22]}$

This illustrates how in its evolution the Periodic Table has adapted to the new intellectual environment based on quantum ideas and incorporated the basic conclusions to provide a deeper insight into why the Periodic Table contains different sized blocks, by recognising the importance of the sub-shells. Moreover, it represented the elements in an effective graphical fashion which also identified for each element the valence orbitals and the number of electrons occupying the sub-shell orbitals. This provides a nice example of survival of the fittest of scientific ideas by the exploitation of new intellectual capital.

To provide a concrete example of the value of the orbital analysis which has resulted from the incorporation of these quantum mechanical ideas we return to the related sphalerite structures in Table 1. The similar cell dimensions in the $\mathrm{Al}$ and $\mathrm{Ga}$ compounds 
Table 2. The role played by the sub-shell filings in determining the overall form of the Periodic Table. Not all elements are shown - see IUPAC 2016 for the full listing.
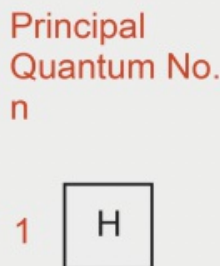

No. of electrons in filled shell

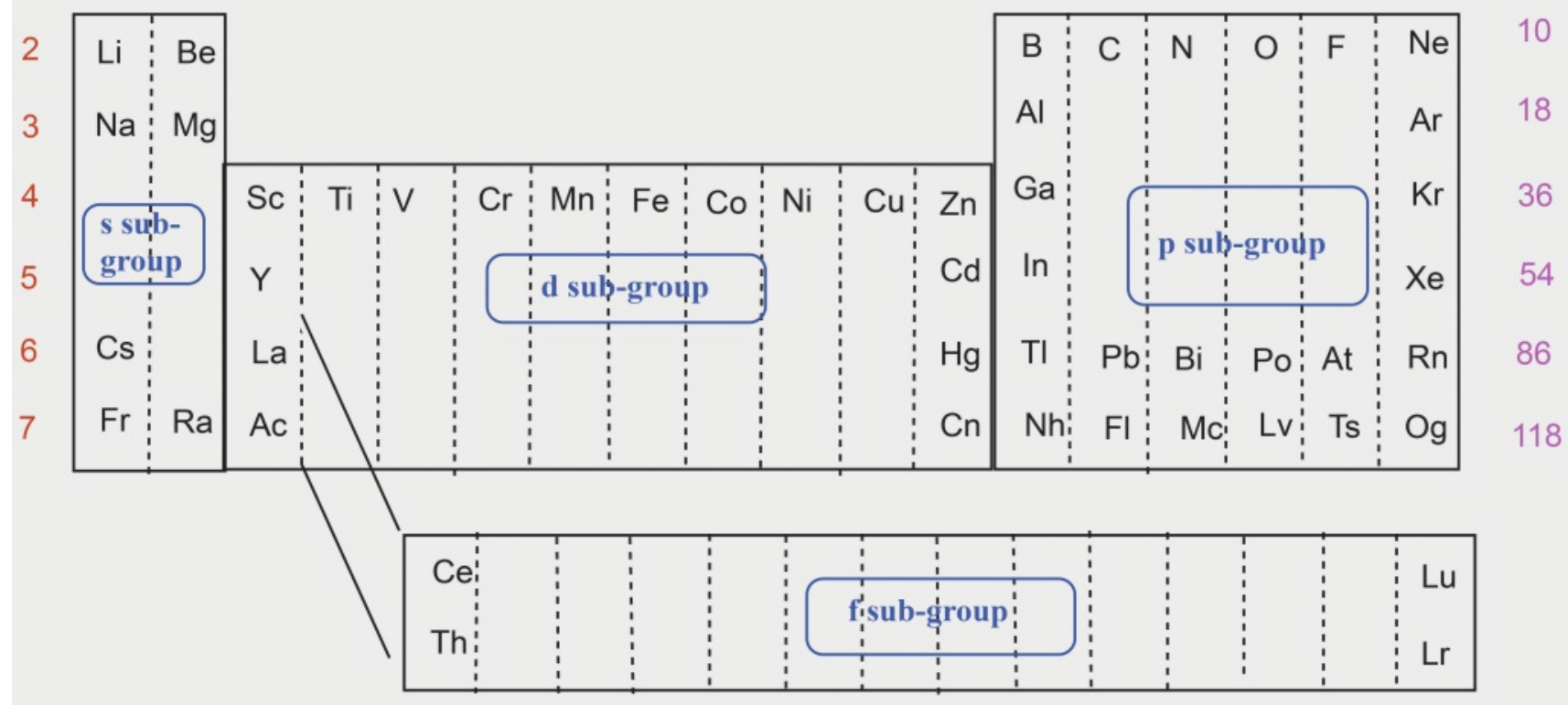

may be related to the fact that Ga has a filled $3 \mathrm{~d}$ shell between the $4 \mathrm{~s}$ and $4 \mathrm{p}$ shells, which increases the atomic number by a further 10 units and incomplete shielding of the valence electrons from the nucleus contracts the $4 s$ and $4 p$ valence orbitals of Ga sufficiently for its atomic radius to be virtually identical to that of $\mathrm{Al}$. A similar contraction occurs between indium (In) and thallium (Tl) when the $4 \mathrm{f}$ shell is filled for the first time. This emphasises the more general point that valence isoelectronic relationships for compounds of elements belonging to the same column of the Periodic Table may lead to compounds with similar valencies and structures, but the detailed understanding of their structures requires a more detailed understanding of the quantum mechanical description of atoms and in particular an understanding of the relative sizes of their valence orbitals and their ability to overlap with the orbitals of atoms to which they are bonded. The development of Density Functional molecular orbital calculations in recent years and their widespread use by experimental chemists has allowed them to address such differences in a more quantitative fashion. ${ }^{[19]}$

It is instructive to give some further attention to the general features of the Periodic Table, illustrated in Table 2. Each of the longer horizontal series of elements is arranged with increasing atomic numbers of the elements from left to right and begins with an alkali metal which has an ns ${ }^{1}$ electron configuration and ends with a noble gas element and the np sub-shell completely filled. The first series has only two elements and involves filling the $1 \mathrm{~s}$ with a single electron for $\mathrm{H}$ and then a pair electrons with opposite spins for He. In this simplest series, the properties of the elements could not be more different. Hydrogen is a very reactive gas, which forms a single covalent bond to itself in the $\mathrm{H}_{2}$ molecule and many other elements, e.g. $\mathrm{FH}, \mathrm{OH}_{2}, \mathrm{NH}_{3}$ and $\mathrm{CH}_{4}$. It may also lose or gain an electron to form the ions $\mathrm{H}^{+}$and $\mathrm{H}^{-}$which either have an empty or filled 1s shell. The latter emulates the He atom which has a closed $1 \mathrm{~s}$ shell. This represents the simplest illustrations of the Lewis-Kossel model whereby the bonding properties of an atom is related to the attainment of the electron configuration of the adjacent inert gas i.e. the basis of the Inert Gas Rule. $\mathrm{He}$ is a monatomic inert gas which does not form any chemical compounds. It has been conventional to place $\mathrm{H}$ above the alkali metals and He above the noble gases in the Periodic Table and thereby emphasise the chemical properties of the elements rather than the aufbau principle. The graphical representation of the Periodic Table when filling the $4 \mathrm{f}$ and $5 \mathrm{f}$ shells according to the aufbau principle results in a block diagram which is much wider because 14 additional elements have to be included. Therefore, it has been conventional to place the f block elements below the central of the Table and indicate their place of entry by connecting lines as shown in Table 2. These changes owe more to artistic and practical teaching considerations than developments in the basic science. In the last hundred years, there have been hundreds of suggestions for presenting the Periodic Table in an alternative way which would be more pedagogically helpful or aesthetically pleasing, but none has stood the test of time.[1]

An important feature of the Periodic Table is that it provides a systematic way of tracing the evolution in chemical and physical properties of elements across series and down columns of the Periodic Table. It also establishes an important connection between the number of electrons in the outer shell and the valencies of the element and use them to understand the structures of molecules and compounds through the chemical bonding ideas developed by Kossel and Lewis.

It also groups elements into the sub-groups shown in Table 2 and emphasises the common chemical characteristics of these groups. Specifically, the s group elements (with the exception of hydrogen) all have chemical properties of low density, highly reactive and reducing electropositive metals. The majority of their 
compounds behave like ionic salts wherein the metals may be described as cations with +1 or +2 charges. The $d$ and $f$ sub-group elements are also all metallic, but are chemically less electropositive and physically have higher melting points and are more dense and sufficiently hard to be used structurally. Across these series and down the columns the $\mathrm{d}$ and f block metals generally behave chemically in a less reducing manner. This leads to the coinage and noble metals occurring at the right-hand corner of the $\mathrm{d}$ block. These elements have compounds in a wider range of oxidation states and form many compounds, which have interesting spectral and magnetic properties. Not all their electrons pair up in a Lewis sense and unpaired electrons persist in their compounds. The $\mathrm{p}$ block does not represent such a coherent group, since they contain elements some of which show typical metallic and others non-metallic properties. The metals and non-metals are not distributed randomly. A diagonal borderline runs across the sub-group which places metals to the left and non-metals to the right. Along the diagonal, the elements show physical and chemical properties which make it difficult to classify them unambiguously as metals or non-metals. Elements such as silicon and germanium, which lie on this borderline are semi-conductors. This property has proved to be so important for the electronic revolution, which has led to lap-top computers and mobile phones. ${ }^{[12]}$

The elements in columns of the Periodic Table have the same number of valence electrons in their outer shells and consequently show great similarities in their compounds. This leads to compounds with the same ratios of atoms (iso-stoichiometric) although they are frequently not isostructural. The heavier elements in the column are generally larger and less inclined to form multiple bonds and this may lead to polymerisation of the basic unit. For example, $\mathrm{CO}_{2}$ is a triatomic linear gaseous molecule, whereas $\left[\mathrm{SiO}_{2}\right]$ has a three-dimensional infinite structure based on tetrahedral $\mathrm{SiO}_{4}$ units and is a solid with a high melting point. The physical and chemical properties of an iso-stoichiometric and iso-structural series of compounds belonging to the same column of the Periodic Table may not follow a linear and regular trend because of the irregular changes in the sizes of the central atom. For example, the ease of formation and chemical properties of $\mathrm{BrO}_{4}^{-}$ are not accurately predicted by taking an average of the properties of $\mathrm{ClO}_{4}^{-}$and $\mathrm{IO}_{4}^{-}$. These changes in atom and orbital sizes can also significantly influence the acid-base and redox properties of these compounds. [14]

The sub-shells defined by the quantum mechanical analysis of polyelectron atoms also shed some light on the occurrence of multiple oxidation states for the heavier main group elements, a phenomenon, described as the 'Inert Pair Effect' by Sidgwick. [23] For example, the observation of two oxidation states for the Group 13-15 metals may qualitatively be attributed to the following alternative electron configurations for the ions shown in Table 3. Each ion has the d sub-shell completely occupied and the lower oxidation state ions result from the filling of the ns sub-shell by an electron pair. The lower oxidation state generally becomes more stable as one descends the column of the Periodic Table. For example, the carbene $\mathrm{CCl}_{2}$ is highly reactive and has to be generated in situ, but the corresponding tin compound $\mathrm{SnCl}_{2}$ is a white crystalline solid which is commonly available on the shelf in a chemistry laboratory. ${ }^{[14]}$

Salts containing the $\mathrm{Au}^{-}$anion, e.g. CsAu known since 1943 completed the isoelectronic series of ions: $\mathrm{Au}^{1-}, \mathrm{Hg}, \mathrm{Tl}^{1+}, \mathrm{Pb}^{2+}$, and $\mathrm{Bi}^{3+}\left(. .[5 \mathrm{~d}]^{10} 6 \mathrm{~s}^{2}\right)$ and have the $6 \mathrm{p}$ shell vacant. ${ }^{[23]}$ The realization that sub-shell completions could lead to stable ions also led to the imaginative synthesis of salts of the alkali metals containing negatively charged metal ions (alkalides) with $\mathrm{ns}^{2}$ electron configurations and specifically $[\mathrm{Na}(2,2,2 \text {-crypt })]^{+} \mathrm{Na}^{-}$and similar salts of the related anions $\mathrm{K}^{-}, \mathrm{Rb}^{-}$and $\mathrm{Cs}^{-} .{ }^{[24]}$

These developments also raise questions concerning the sharp distinction made initially by Lewis and Kossel concerning core
Table 3. Sub-shell fillings for groups 13-15

\begin{tabular}{|c|c|c|c|}
\hline Group 13 & Group 14 & Group 15 & $\begin{array}{c}\text { Electronic } \\
\text { configuration }\end{array}$ \\
\hline $\mathrm{Ga}^{3+}$ & $\mathrm{Ge}^{4+}$ & $\mathrm{As}^{5+}$ & {$[3 \mathrm{~d}]^{10}$} \\
\hline $\mathrm{Ga}^{1+}$ & $\mathrm{Ge}^{2+}$ & $\mathrm{As}^{3+}$ & {$[3 \mathrm{~d}]^{10} 4 \mathrm{~s}^{2}$} \\
\hline $\mathrm{In}^{3+}$ & $\mathrm{Sn}^{4+}$ & $\mathrm{Sb}^{5+}$ & {$[4 \mathrm{~d}]^{10}$} \\
\hline $\mathrm{In}^{1+}$ & $\mathrm{Sn}^{2+}$ & $\mathrm{Sb}^{3+}$ & {$[4 \mathrm{~d}]^{10} 5 \mathrm{~s}^{2}$} \\
\hline $\mathrm{Tl}^{3+}$ & $\mathrm{Pb}^{4+}$ & $\mathrm{Bi}^{5+}$ & {$[5 \mathrm{~d}]^{10}$} \\
\hline $\mathrm{Tl}^{1+}$ & $\mathrm{Pb}^{2+}$ & $\mathrm{Bi}^{3+}$ & {$[5 \mathrm{~d}]^{10} 6 \mathrm{~s}^{2}$} \\
\hline
\end{tabular}

and valence electrons. Their interpretation of the regularities in the Periodic Table depended on atoms belonging to the same column of the Periodic Table having a common number of valence electrons with comparable bonding abilities and the core electrons remaining detached from chemical bonding. The quantum mechanical studies showed the sub-shells of atoms interweaved and were not dominated by a single quantum number. Thus, the $3 \mathrm{~d}$ shell is filled at the same time as the $4 \mathrm{~s}$ shell and before the $4 \mathrm{p}$ shell. The filled $\mathrm{d}$ and $\mathrm{f}$ sub-shells have smaller radii than the $\mathrm{s}$ and $\mathrm{p}$ shells which they intersperse and consequently are not able to participate as effectively in covalent bonding. The transition metals have (n-1)d orbitals which are more core-like than the ns and np orbitals and consequently they have many compounds with the same formula and in ionic compounds similarly charged metal cations. ${ }^{[12-14]}$ The metal ions in these compounds have partially filled d shells which lead to interesting spectral and magnetic properties. The f orbitals of the lanthanides and actinides are even more core-like and their compounds show even more similar chemical properties. In summary, for these elements the semicore-like nd and nf orbitals lead to important horizontal as well as vertical relationships in the Periodic Table for the transition metals, lanthanides and actinides. ${ }^{[12]}$

Electron diffraction studies in the gas phase have shown that beryllium and magnesium dihalides and $\mathrm{CaCl}_{2}, \mathrm{CaBr}_{2}$ and $\mathrm{CaI}_{2}$, $\mathrm{SrBr}_{2}$ and $\mathrm{SrI}_{2}$ all have linear geometries, however $\mathrm{CaF}_{2}, \mathrm{SrF}_{2}$ and $\mathrm{SrCl}_{2}$ and the barium dihalides have angular geometries. Although these simple metal ions are valence isoelectronic, the large electropositive metals when combined with small electronegative halides favour bent structures. It has been suggested that this also results from the interweaving of orbitals discussed above. Specifically the lighter elements have $n s$ and $n p(n=2,3)$ valence orbitals whereas the heavier elements have ns and (n-1) d $(n>3)$ valence orbitals, which favour geometries which are not centrosymmetric and use the $\mathrm{s}$ and $\mathrm{d}$ orbitals for bond formation. In summary, the geometric comparisons of molecules in the same group have to take into account the sub-shell structure and valence orbitals available to the atoms as well as the sizes of the ions. ${ }^{[25,26]}$

\section{Isoelectronic Relationships in Covalent Molecules}

Langmuir played a very important role in the adoption of Lewis' electron pair bond concept through his persuasive lectures, clearly written papers and his coining of new words, which captured the essence of complex concepts. ${ }^{[27-33]}$ Indeed it was he who first proposed the description 'covalent bond' which gained wider acceptance than Lewis' 'chemical bond' and preferred by Pauling in 'The Nature of the Chemical Bond', ${ }^{[34]}$ which recast the Lewis-Kossel ideas in a quantum mechanical theoretical framework. Langmuir also contributed some original concepts, which enhanced and broadened the scope of the Lewis-Kossel model. For example, he extended the octet rule to the 18 electron rule 
which encompassed many interesting molecular compounds of the transition metals. ${ }^{[35,36]}$ Exactly 100 years ago he showed that the isoelectronic relationships between ions, noted by Kossel and Lewis, could be extended to molecular species.[28-30] "The octet theory of valence indicates that if compounds having the same number of atoms have also the same total number of electrons, the electrons may arrange themselves in the same manner. In this case the compounds or groups of atoms are said to be isosteric. Such compounds should show remarkable similarity in physical properties, that is, in those properties which do not involve a separation of the atoms in the molecule." His descriptor 'isosteric' has virtually disappeared from the lexicon of modern valence theory, ${ }^{[36]}$ but the essential idea has been retained in the 'isoelectronic' descriptor. ${ }^{[37]}$

As molecular orbital theory ${ }^{[38,39]}$ emerged more clearly as an alternative quantum mechanical description for describing chemical bonding in the 1950s the isoelectronic description of isostructural molecules became more commonplace. ${ }^{[25-28]}$ The molecular orbital methodology, based on an aufbau filling of delocalized molecular energy levels, rather than the designation of specific two-centre two-electron bonds, found it more natural to highlight the total number of valence electrons in a molecule and draw attention to the chemical similarities between molecules with the same number of electrons (i.e. isoelectronic molecules). Spectroscopists and structural chemists found it particularly useful to focus attention on isoelectronic series in order to limit the number of variables when comparing the force constants and bond lengths in related molecules and ions. ${ }^{[37]}$

The molecules and ions summarized in Table 4 give a preliminary indication of the usefulness of 'isoelectronic' as a unifying concept. All the classes of molecules and ions have the same total number of valence electrons and are isostructural. It is noteworthy that the numbers of examples of isoelectronic molecules are particularly numerous for linear triatomic $\mathrm{AX}_{2}$, tetrahedral $\mathrm{AX}_{4}$, and octahedral $\mathrm{AX}_{6}$ molecules and ions with 16, 32 and 48 valence electrons. The examples in the same rows of Table 4 are strictly isoelectronic. There are many more examples of valence isoelectronic molecules which are isostructural, but not shown in the Table. If a single atom is replaced by an adjacent atom in the Periodic Table then the isoelectronic relationship dictates that the charge on the species must change by -1 if the replacing atom lies to the left and +1 if it lies on the right, e.g. $\mathrm{CN}^{-}, \mathrm{N}_{2}$ and $\mathrm{NO}^{+}$. Simultaneous replacement of two adjacent atoms by one from the left and one from the right dictates that the molecule retains the same charge, e.g. $\mathrm{N}_{2}$ and $\mathrm{CO}$ and $\mathrm{N}_{2} \mathrm{O}$ and $\mathrm{CO}_{2} \cdot{ }^{[28-30]}$ As Langmuir originally observed, molecular pairs such as these have remarkably similar physical and chemical properties. This is analogous to the isoelectronic replacements noted above for semiconducting compounds in Table 1. ${ }^{[21]}$ If the substitution results in a pair of adjacent atoms separated by more than three places in the Periodic Table, e.g. in BF, which is isoelectronic with $\mathrm{N}_{2}$, then the large difference in electronegativity reduces the degree of covalency and the molecule is significantly more reactive. High yields of $\mathrm{BF}$ have been obtained by passing $\mathrm{BF}_{3}$ over crystalline boron at $2000{ }^{\circ} \mathrm{C}$ and $1 \mathrm{~mm}$ pressure, but the $\mathrm{BF}$ molecules condense to form a green polymer at $-196^{\circ} \mathrm{C}$. The long bond length in $\mathrm{BF}$ of $1.263 \AA$

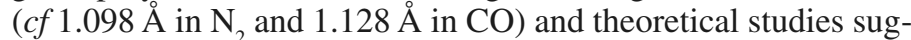
gest that the $\mathrm{BF}$ bond order is much less than $3 .{ }^{240,41]}$ The value of the isoelectronic relationship with $\mathrm{CO}$ and $\mathrm{N}_{2}$ still has some utility because the $\mathrm{BF}$ molecule can be trapped as a stable species when it binds to a transition metal, e.g. $\left[\{\mathrm{CpRu}(\mathrm{CO})\}_{2}(\mu-\mathrm{BF})\right] .{ }^{[42]}$

The molecules belonging to the classes of isoelectronic molecules in Table 4[12,37] share common three-dimensional structures, but not identical bond lengths. In the higher symmetry examples the bond angles are identical by symmetry, but when the symmetry is lower some variations in bond angles are observed. For example, in $\mathrm{AB}_{2}$ angular species the $\mathrm{B}-\mathrm{A}-\mathrm{B}$ bond angle is $144^{\circ}$
Table 4. Examples of isoelectronic and isostructural molecules and ions $\mathrm{AB}_{\mathrm{n}}(\mathrm{n}=1,2,4$ and 6$)$.

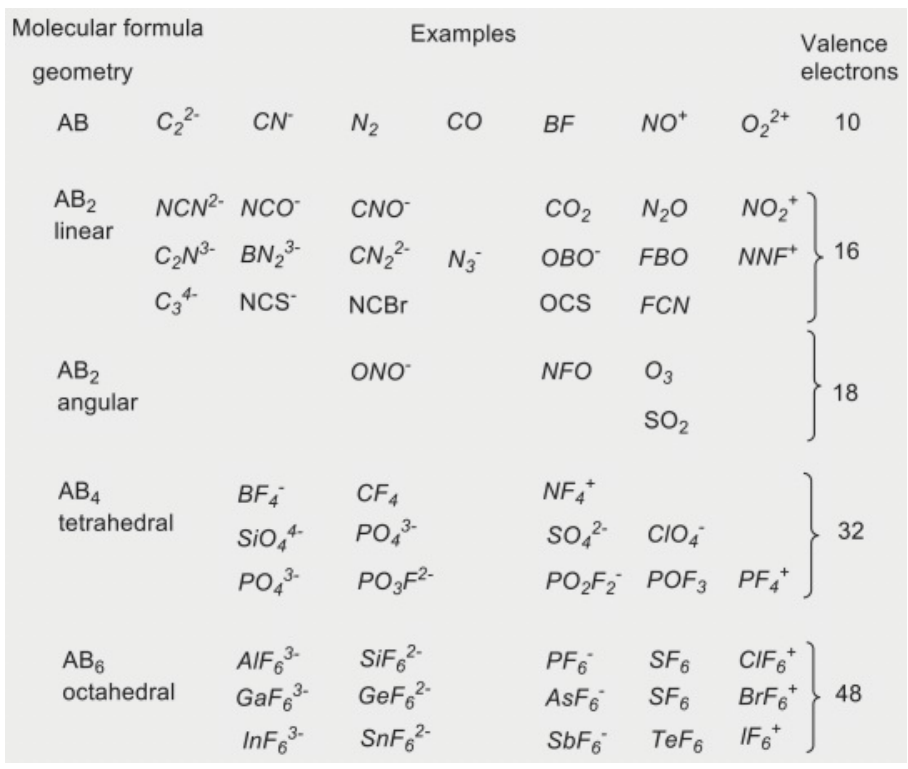

in $\mathrm{O}\left(\mathrm{SiH}_{3}\right)_{2} ; 111.7^{\circ}$ in $\mathrm{OMe}_{2} ; 111.2^{\circ}$ in $\mathrm{OCl}_{2} ; 104.5^{\circ}$ in $\mathrm{OH}_{2}$ and $103.1^{\circ}$ in $\mathrm{OF}_{2}{ }^{[25]}$

Although the species in Table 4 are structurally related by the isoelectronic principle, the total charge on the species may result in very different chemical properties. In order to isolate a particular compound as a stable entity under ambient conditions it is necessary for it to be thermodynamically stable and, if not, kinetically inert. If the negative charge is increased by isoelectronic atom substitutions such as those described above then the resulting species will be more nucleophilic and generally stronger reducing agents. The introduction of a larger positive charge on the species results in it becoming more electrophilic and a stronger oxidising agent. ${ }^{[12]}$ With this in mind, it is noteworthy that for the simpler water-soluble examples shown in Table 4 the charges on the ions rarely exceed $+/-3$, but less reactive solvents may lead to more highly charged species.

In the last 150 years chemists have learned many tricks to isolate molecules which are not accessible under ambient conditions and therefore Table 4 includes examples of such molecules and isoelectronic ions. The most noteworthy modern techniques are matrix isolation, less-reactive solvents and atmospheres and using high temperatures and low pressures in the gas phase. In matrix isolation ${ }^{[43,44]}$ the reactive molecule is generated in a low temperature matrix made from inert gases and the resultant species are studied by spectroscopic techniques. A variation of this is to make highly charged ions in the solid state using reaction techniques which eliminate the presence of reactive reagents, e.g. water and $\mathrm{O}_{2}{ }^{[11]}$ For organometallic reagents it is common to use non-reactive solvents and undertake the reactions under an inert gas atmosphere and, if necessary, at lower temperatures. ${ }^{[45]}$ Molecules which are valence isoelectronic may also exhibit very different reactivities. For example, $\mathrm{O}_{3}$ and $\mathrm{SO}_{2}$ are valence isoelectronic and share a common formula and molecular shape, but the former is a strong oxidising agent, and used in swimming pools to kill bacteria, whereas the latter is a reducing agent (used in the wine industry to limit aerial oxidation). The valence isoelectronic replacements may also lead to large differences in the hard and soft character of acids and bases and for example, organophosphines are much softer Lewis bases than organoamines. ${ }^{[46,47]}$

In the following sections the value of isoelectronic relationships in the creative synthesis of new compound types during the last century is discussed. This concept has provided the starting 
point for many new exploratory research projects and the new compounds which have been synthesised have enriched the subject immeasurably.

\section{Noble Gas Compounds}

Bartlett's discovery of the first noble gas compound in 1962 resulted from his observation that $\mathrm{PtF}_{6}$ was able to oxidize $\mathrm{O}_{2}$ to $\mathrm{O}_{2}{ }^{+}$and he reasoned that since $\mathrm{O}_{2}$ and $\mathrm{Xe}$ had similar ionization energies then $\mathrm{PtF}_{6}$ might be sufficiently oxidizing to free Xe from the shackles of its description as an inert gas. ${ }^{[48]}$ This eureka moment must have been like the alchemists' discovery that gold dissolved in aqua regia. His very short paper reporting the first compound $\left[\mathrm{XePtF}_{6}\right]$ initiated a scramble to make other compounds of the noble gases. Those laboratories, which were equipped to handle strong oxidizing agents such as fluorine, had a head start in the race. Within a matter of months a range of xenon fluorine compounds had been isolated and their hydrolysis led to the first xenon oxygen compounds. ${ }^{[49,50]}$ This rapid progress was assisted conceptually, because a wide range of iodine fluorides, chlorides and oxides had been known for several decades and it did not require too much imagination to think that $\mathrm{IF}_{2}^{-}$and $\mathrm{IF}_{4}{ }^{-}$may have isoelectronic analogues in $\mathrm{XeF}_{2}$ and $\mathrm{XeF}_{4}$. Table 5 summarises the wide range of xenon compounds which resulted and underpins not only the important isoelectronic relationships between iodide and xenon, but its extension to other members of the same row of the Periodic Table, viz. Te and Sb. Of course it also led to the study of analogous compounds of krypton and radon.

\section{Isoelectronic Ring and Polyhedral Molecules}

The importance of benzene and other aromatic molecules in the development of organic chemistry encouraged inorganic chemists to explore the possibility of making inorganic analogues and determine whether they underwent similar electrophilic substitution chemistries. Fig. 1 illustrates how this search resulted in many inorganic ring compounds, which are isoelectronic and have $6 \pi$ electrons in accordance with the Hückel $4 n+2$ rule. [39] Some of the inorganic examples involve the simple isoelectronic replacement based on $\mathrm{HC}=\mathrm{CH}$ fragments of benzene by $\mathrm{HB}=\mathrm{NH}$ (still described as an isosteric replacement in the pharma-litera- ture ${ }^{[36]}$ ) or $\mathrm{HB}=\mathrm{O}$. When their chemistries were studied in detail the majority were found not to undergo a wide range of substitution reactions. NMR spectroscopic measurements, nevertheless confirmed some cyclic delocalization, although not as extensive as that in benzene. ${ }^{[7,14,51-53]}$

Other examples of inorganic cyclic molecules with $4 n+26 \pi$ electrons are also shown in Fig. 1. Some of these examples have large positive or negative charges, e.g. $\mathrm{Se}_{4}{ }^{2+}$ and $\mathrm{Si}_{5}{ }^{6-}$ have been isolated by using either super-acid, strongly basic conditions or solid state syntheses. ${ }^{[11,51]}$

Inorganic chemists have known for nearly a century that elemental sulphur has allotropes based on ring compounds, and this area has been extended greatly by using isoelectronic relationships. ${ }^{[11,51]}$ All the examples of ring compounds in Fig. 2 have $6 \mathrm{n}$ valence electrons. The isoelectronic relationships may also be achieved by the incorporation of organic substituents,

Total electron

count, $\mathrm{t}$
30<smiles>c1ccccc1</smiles>

$\mathrm{C}_{6} \mathrm{H}_{6}$ Benzene

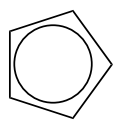

$\mathrm{C}_{5} \mathrm{H}_{5}$

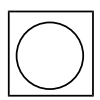

$\mathrm{C}_{4} \mathrm{H}_{4}{ }^{2-}$<smiles>c1ccncc1</smiles>

$\mathrm{NC}_{5} \mathrm{H}_{5}$

Pyridine<smiles>b1nbnbn1</smiles>

$\mathrm{B}_{3} \mathrm{~N}_{3} \mathrm{H}_{6}$ Borazine

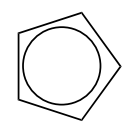

$\mathrm{P}_{5}{ }^{-} \quad \mathrm{As}_{5}{ }^{-} \mathrm{Sb}_{5}$

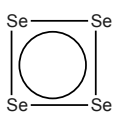

$\mathrm{Se}_{4}{ }^{2+}$

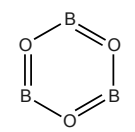

$\mathrm{B}_{3} \mathrm{O}_{3} \mathrm{H}_{3}$

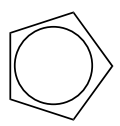

$\mathrm{Si}_{5}{ }^{6-}$

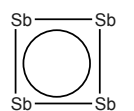

$\mathrm{Sb}_{4}{ }^{2-}$<smiles>c1ncncn1</smiles>

$\mathrm{C}_{3} \mathrm{~N}_{3} \mathrm{H}_{3}$

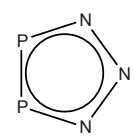

$\mathrm{P}_{2} \mathrm{~N}_{3}$

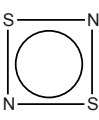

$\mathrm{N}_{2} \mathrm{~S}_{2}$
Fig. 1. Examples of isoelectronic and valence isoelectronic analogues of aromatic organic molecules. In this and subsequent Figures, $t$ represents the total number of valence electrons in the molecule. ${ }^{[51]}$

Table 5. Examples of xenon and krypton fluorides and oxides and isoelectronic molecules. The total number of valence electrons, $\mathrm{t}$, and their geometries are given in column 1.

\section{t, total no. of} valence electrons

$\mathrm{AX}$ Linear $\mathrm{t}=22$

$\mathrm{AX}_{3}$ planar $\mathrm{C}_{2 \mathrm{v}} \mathrm{t}=28$

$\mathrm{AX}_{4}$ square-planar $\mathrm{t}=36$

$\mathrm{AX}_{4}$ pyramidal $\mathrm{C}_{2 \mathrm{v}} \mathrm{t}=34$

$\mathrm{AX}_{6}$ distorted octahedral $\mathrm{t}=50$

$\mathrm{AX}_{3}$ pyramidal $\mathrm{t}=26$

$\mathrm{AX}_{5}$ square pyramidal $\mathrm{t}=42$

$\mathrm{AX}_{4}$ tetrahedral $\mathrm{t}=32$
$\mathrm{XeOF}_{4}, \mathrm{XeF}_{5}^{+}$

\section{Noble gas compound}

\begin{tabular}{l|l}
$\mathrm{XeF}_{2}, \mathrm{KrF}_{2,}$ & $\mathrm{IF}_{2}^{-} \mathrm{ICl}_{2}^{-}$ \\
$\mathrm{XeF}_{3}^{+}, \mathrm{XeOF}_{2}^{*}$ & $\mathrm{IF}_{3}$ \\
\hline $\mathrm{XeF}_{4}$ & $\mathrm{IF}_{4}^{-}$ \\
\hline $\mathrm{XeF}_{2} \mathrm{O}_{2}$ & $\mathrm{IF}_{2} \mathrm{O}_{2}^{-} \mathrm{IF}_{4}^{+}$ \\
\hline $\mathrm{XeF}_{6}, \mathrm{XeO}_{6}^{4-}$ & $\mathrm{IF}_{6}^{-}$ \\
\hline $\mathrm{XeO}_{3}$ & $\mathrm{IO}_{3}^{-}$ \\
\hline $\mathrm{XeOF}_{4}, \mathrm{XeF}_{5}^{+}$ & $\mathrm{TeO}_{3}^{2-}$ \\
& $\mathrm{SbF}_{5}^{2-}$ \\
\hline $\mathrm{XeO}_{4}$ & $\mathrm{SbCl}_{5}^{2-}$ \\
& $\mathrm{IO}_{4}^{-}$ \\
& $\mathrm{IO}_{3} \mathrm{~F}^{--}$ \\
& $\mathrm{TeO}_{2} \mathrm{~F}_{2}$ \\
& $\mathrm{SbOCl}_{3}$
\end{tabular}

\section{Valence isoelectronic analogues}

$\mathrm{ClF}_{2}{ }^{-} \mathrm{Cl}_{3}^{-}$

$\mathrm{BrF}_{3}$

$\mathrm{ClF}_{3}$

$\mathrm{BrF}_{4}$

$\mathrm{SF}_{4} \mathrm{ClF}$

$\mathrm{SeCl}_{6}{ }^{2-}$

$\mathrm{SO}_{3}{ }^{2-}$

$\mathrm{SO}_{2} \mathrm{~F}^{-} \mathrm{SF}_{3}^{+}$

$\mathrm{TeF}_{5}$

$\mathrm{SeF}_{4} \mathrm{BrF}_{4}^{+}$

$\mathrm{PF}_{4}^{-} \mathrm{A}_{\mathrm{S}} \mathrm{F}_{4}$

$\mathrm{BiBr}_{6}{ }^{3}$

$\mathrm{ClO}_{3}$

$\mathrm{NF}_{3}$

$\mathrm{BrO}_{3}^{-}$

$\mathrm{PF}_{3} \mathrm{SbF}_{3}$

$\mathrm{ClF}_{5}$

$\mathrm{BrF}_{5}, \mathrm{IF}_{5}$

$\mathrm{ClO}_{4}^{-}$

$\mathrm{ClO}_{3} \mathrm{~F}$

$\mathrm{BrO}_{4}^{-}$

$\mathrm{SO}_{4}{ }^{2-}$

$\mathrm{SO}_{2} \mathrm{~F}_{2}$

$\mathrm{BrO}_{3} \mathrm{~F}$

$\mathrm{PO}_{4}^{3-}$

$\mathrm{SeO}_{2} \mathrm{~F}_{2}$

$\mathrm{SiO}_{4}^{4}$

$\mathrm{POCl}_{3} \mathrm{~F}, \mathrm{Br} \quad \mathrm{AsOCl}_{3}$ 
which replace a lone pair by an $\mathrm{M}-\mathrm{R}$ bond, e.g. in $\mathrm{Sn}_{6} \mathrm{Me}_{12}$ and $\mathrm{As}_{5} \mathrm{Me}_{5}$, although the size of the organic substituent can also influence the size of the ring. $\mathrm{Sn}_{6} \mathrm{Me}_{12}$ is a valence isoelectronic analogue of hexamethyl cyclo-hexane. Fig. 2 illustrates the large range of isoelectronic ring compounds and those rings containing two or more different atoms, e.g. $\mathrm{S}_{6}(\mathrm{NH})_{2}$ have isomeric possibilities.

When an electron pair is added to such ring molecules then generally it is formally added to one specific bond and the ring breaks to form a chain. The two additional lone pairs now reside on the atoms at the ends of the chain and make these centres highly nucleophilic. Fig. 3 gives examples of such chain molecules with 3-6 atoms and $6 n+2$ valence electrons. As with ring compounds there are additional examples, where the primary atoms are bonded to hydrogen or organic radicals, but the total valence electrons remain the same as long as the $\mathrm{H}$ or $\mathrm{R}$ radicals are designated as 1 electron donors, i.e. $\mathrm{P}-\mathrm{H}$ and $\mathrm{As}-\mathrm{Ph}$ are electronically equivalent to $\mathrm{S}$ and $\mathrm{Se}$. These anionic chain compounds have been shown to act as chelating ligands towards metal ions, e.g. $\left[\operatorname{Pt}\left(\mathrm{S}_{5}\right)_{3}\right]^{2-}$, which is asymmetric and whose optical enantiomers may be resolved.

The $\mathrm{P}_{4}{ }^{[11,51-53]}$ molecule is based on a three-dimensional tetrahedron and each phosphorus atom is connected to three oth- er phosphorus atoms. This represents the simplest example of a series of three-connected polyhedral molecules with an even number of vertices and 5n valence electrons. Examples of such molecules and their related organic analogues, e.g. tetrahedrane, prismane and cubane, are shown in Fig. 4. In those polyhedral molecules $M_{n} R_{n}$ the steric requirements of the $R$ group play a significant role in determining the nuclearity of the polyhedral molecule obtained from the synthetic procedure, with larger groups favouring the smaller polyhedral clusters $M_{n} R_{n}$. Addition of an electron pair to a three-connected molecule generally results in the breaking of one of the cluster bonds in much the same as that discussed above for ring compounds. The resulting ions have $5 n+2$ valence electrons

The final important class of inorganic polyhedral molecules are those which have exclusively triangular faced polyhedra with approximately spherical shapes. ${ }^{[54-64]}$ Borane polyhedral molecules, $\left[\mathrm{B}_{\mathrm{n}} \mathrm{H}_{\mathrm{n}}\right]^{2-}$ provided a great challenge to valence theory in the 1950s and 1960s because the number of faces [2(n-2)] and edges [3(n-2)] did not map onto localised Lewis two-centre two-electron bond descriptions. The deltahedral borane anions $\left[\mathrm{B}_{n} \mathrm{H}_{n}\right]^{2-}$ and the isoelectronic carboranes $\left[\mathrm{B}_{n} \mathrm{C}_{2} \mathrm{H}_{n+2}\right]$ are characterised by a total of $4 n+2$ valence electrons (see Fig. 5). The bonding in these molecules is highly delocalised in much the
Fig. 2. Examples of inorganic ring molecules based on main group atoms. ${ }^{[11,51]}$ The large negative charges on some of the Group 15 examples are noteworthy. $n=3 \quad t=18$<smiles>[R][Sb]1[Se][R]1([R5])[R5]</smiles>

$n=4 t=24$

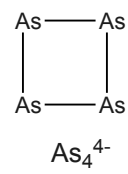
$n=5 \quad t=30$

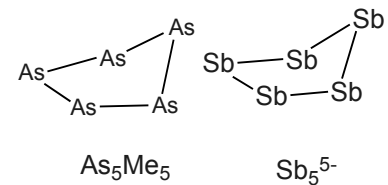
$n=6 \quad t=36$<smiles>S1SSSSS1</smiles><smiles>[pH]1[pH][pH][pH][pH]1</smiles><smiles>[As]1[As][As][As]1</smiles>
$\mathrm{S}_{6}$ $P_{6}{ }^{6-}$ $\mathrm{As}_{6} \mathrm{Me}_{6}$ $n=8 t=48$<smiles>s1ssssss1</smiles>
$\mathrm{S}_{8}$<smiles>[B]1[B][B][B][B]1</smiles>
$\mathrm{Sb}_{8}^{8-}$<smiles>C1[Se]C[Se][Se]1</smiles>

$\mathrm{Se}_{3} \mathrm{C}_{3} \mathrm{H}_{6}$<smiles>N1SSSSSSS1</smiles>

$\mathrm{S}_{6}(\mathrm{NH})_{2}$

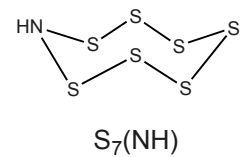<smiles>[Se]1[Sn][Sn][Sb]1</smiles>
$\mathrm{Sn}_{6} \mathrm{Me}_{12}$

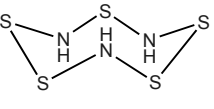

$\mathrm{S}_{5}(\mathrm{NH})_{3}$
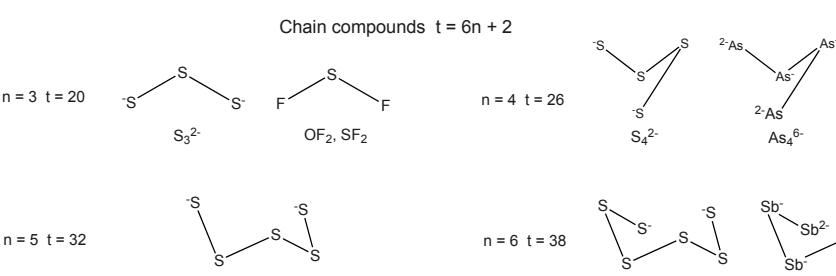

$\mathrm{S}_{5}{ }^{2-}$

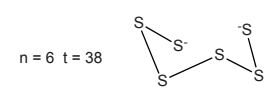

$\mathrm{S}_{6}^{2-}$

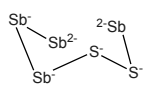

$\mathrm{Sb}_{6}{ }^{8-}$
Fig. 3. Examples of inorganic chain compounds. ${ }^{[11,51]}$

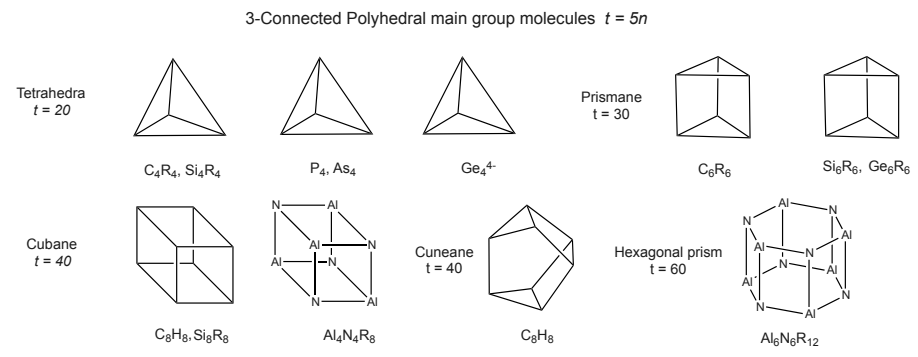

Fig. 4. Examples of three-connected polyhedral inorganic molecules. For the tetrahedron, the trigonal prism and the cube isoelectronic analogues are shown. ${ }^{[11]}$ same way as the $\pi$-systems in aromatic molecules and their relative electron deficiency necessitates the maximum sharing of electrons with as many neighbours as possible. The spherical deltahedra are able to achieve this requirement. The parent closo- deltahedral borane anions are well characterised for $\mathrm{n}=$ 5-12. Examples of isoelectronic icosahedral closo- boranes with 50 valence electrons are illustrated in Fig. 6. The icosahedral dicarbaboranes have three possible isomers described as ortho-, meta- and para-isomers by analogy with disubstituted benzene derivatives. Besides the dicarbaboranes, phospha-carboranes and thia-boranes have been isolated. More recently spherical carboranes with more than 12 vertex atoms have been characterised. ${ }^{[65]}$

The related neutral boranes $\left[\mathrm{B}_{\mathrm{n}} \mathrm{H}_{\mathrm{n}+4}\right]$ and $\left[\mathrm{B}_{\mathrm{n}} \mathrm{H}_{\mathrm{n}+6}\right]$ have $(4 \mathrm{n}+4)$ and $(4 n+6)$ valence electrons. These structures are described as nido- and arachno- and examples are illustrated in Figs. 5 and 6 . They represent fragments of the parent deltahedra with 1 vertex (nido-) and two vertices missing (arachno-) from the parent deltahedron. ${ }^{[54,55]}$ The parent closo- deltahedral borane anions are well characterised for $\mathrm{n}=5-12$, and the majority of related nido- and arachno- species are known for the boranes or isoelectronic carboranes. Fig. 6 illustrates the almost complete isoe- 
lectronic series of nido- boranes, carboranes, and hydrocarbons based on a nido- pentagonal bipyramid. All the isoelectronic molecules and ions have 28 valence electrons (see Fig 6).

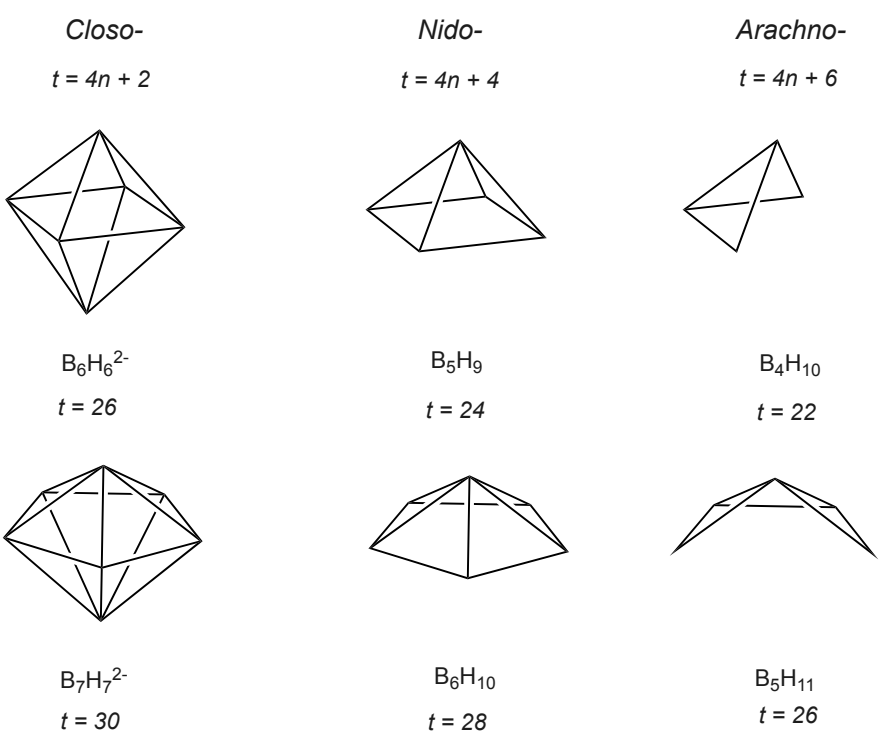

The closely related Zintl compounds feature naked anionic clusters of the p block metals and semi-metals that are generated by the reduction of heavy main group $p$ elements with alkali metals. ${ }^{[1]}$ They are synthesised in anhydrous liquid ammonia or ethylenediamine. Examples include; $\left[\mathrm{Bi}_{3}\right]^{3-},\left[\mathrm{Sn}_{0}\right]^{4-},\left[\mathrm{Pb}_{9}\right]^{4-}$, and $\left[\mathrm{Sb}_{7}\right]^{3-}$. And they generally have closo-, nido-, and arachno- structures with $4 n+2,4 n+4$ and $4 n+6$ valence electrons/respectively. The metal atoms have a lone pair associated with each atom and in this respect they resemble $\mathrm{P}_{4}$. Examples are illustrated in Fig. 7. The high negative charges associated with these ions is noteworthy.[11,57]

One significant advantage of these isoelectronic relationships is that they are independent of specific chemical bonding models and the deltahedra, which cannot be described by localised covalent bonds, can be interrelated to other polyhedral and cyclic molecules of other $\mathrm{p}$ block elements.

\section{Isoelectronic but not Isostructural Molecules}

The discussion above has illustrated how isoelectronic relationships have been used to enlarge and interconnect the landscape of the Periodic Table. In recent times the concept has become a victim of its own success and it has become common in modern inorganic textbooks to promote the following definition of isoelectronic series "molecules which are isoelectronic have

Fig. 5. Examples of closo-, nido- and arachno-boranes.

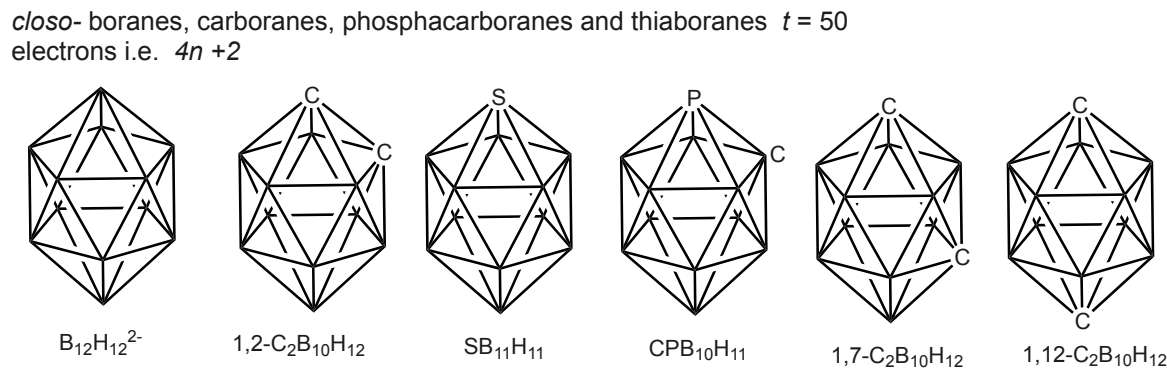

nido- boranes and carboranes $\mathrm{B}_{\mathrm{n}} \mathrm{C}_{6-\mathrm{n}} \mathrm{H}_{\mathrm{n}+4} \quad t=28$ electrons i.e. $4 n+4$

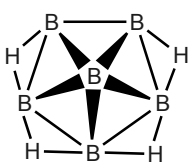

$\mathrm{B}_{6} \mathrm{H}_{10}$

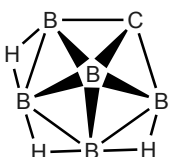

$\mathrm{CB}_{5} \mathrm{H}_{9}$

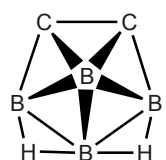

$\mathrm{C}_{2} \mathrm{~B}_{4} \mathrm{H}_{8}$

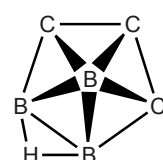

$\mathrm{C}_{3} \mathrm{~B}_{3} \mathrm{H}_{7}$

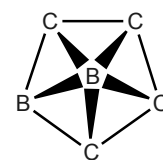

$\mathrm{C}_{4} \mathrm{~B}_{2} \mathrm{H}_{6}$

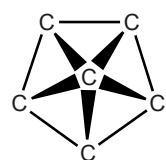

$\mathrm{C}_{6} \mathrm{Me}_{6}{ }^{2+}$

Fig. 6. In the first row isoelectronic substituted boranes with icosahedral geometries are shown. The second row shows examples of nido-pentagonal prismatic molecules which constitute an almost complete isoelectronic series with 28 valence electrons from borane to hydrocarbon cation.

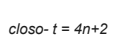

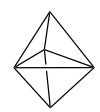
$\left[\mathrm{Si}_{5}\right]^{2-},\left[\mathrm{Sn}_{5}\right]^{2 *}$, 22

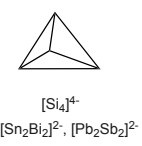

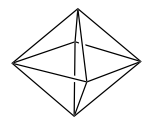

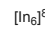

26

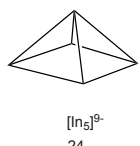

$\left[\ln _{5}\right]^{9}$
24

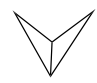

Fig. 7. Examples of Zintl ions which conform to the closo-, nido- and arachno generalisation. a high probability of being isostructural". ${ }^{6-14]}$ This is an oversimplification and understates the extent to which the different classes of inorganic molecules can overlap to generate isoelectronic molecules with alternative structures. Fig. 8 summarises the alternative structures for isoelectronic inorganic and organic molecules with 4 atoms and 22 valence electrons. The majority of examples are strictly isoelectronic (in red), but there are also some examples in green, which are valence-isoelectronic. Since the Langmuir definition of isoelectronic is based on the number of heavy atoms, molecules containing hydrogen atoms have been included. A lone pair and a $\mathrm{M}-\mathrm{H}$ bond both involve a single electron pair so that the latter is equivalent to a protonated lone pair and consequently $\mathrm{M}$ : and $\mathrm{M}-\mathrm{H}^{+}$are interchangeable. The first column of Fig. 8 confirms that substitution of $\mathrm{F}$ or $\mathrm{O}^{-}$by $\mathrm{CH}_{3}$ does not alter the heavy atom skeletal structure. ${ }^{[6-14]}$

It will come as a surprise to many that although the molecules in Fig. 8 have been restricted to 4 heavy atoms and 22 valence electrons, 7 distinct structural types have been structurally characterised. The structural differences between the isoelectronic 
molecules are not trivial and arise from different bond multiplicities, linear and bent geometries, and the presence of three- and four-membered ring compounds. The different structural classes arise primarily from the alternative locations of the bonds and lone pairs, both of which are stereochemically active in the majority of main group molecules. These permutations are summarized at the top of each column in Fig. 8, i.e. 1 triple plus two single; 2 double plus 1 single; 1 double plus 3 single and 5 single bonds and within each of these classes the bonds may also be arranged differently, e.g. in columns 2 and 3 of Fig. 8. These alternative structures arise because the total electron count can result from more than one structural class. For example, $\mathrm{B}_{4} \mathrm{H}_{10}$ may be described as an arachno- borane with $4 \mathrm{n}+6\left(\mathrm{n}=4 \mathrm{t}=22\right.$ electrons) and $\mathrm{P}_{4}{ }^{2-}$ is related to a deltahedral $\mathrm{P}_{4}$ which is associated with $5 \mathrm{n}$ valence electrons ( $\mathrm{n}$ $=4 \mathrm{t}=20$ ) and addition of an electron pair (leading to $\mathrm{t}=5 \mathrm{n}+2$ ) breaks 1 bond to give the same butterfly structure observed for the heavy atoms in $\mathrm{B}_{4} \mathrm{H}_{10}$ ( see Section 5 above and Figs 4 and 5).

All the examples, with the exception of $\mathrm{B}_{4} \mathrm{H}_{10}$ obey the octet rule and the molecules and ions in Fig. 8 may be represented by classical Lewis bonds and lone pairs and have the same number of bonds and lone pairs, i.e. 5 covalent bonds, $\mathbf{B}$, and 6 lone pairs, Lp. Straightforward algebra shows that the Lewis structures in Fig. 8 are governed by the following two key equations which uniquely define $\mathbf{L} \mathbf{p}$ and $\mathbf{B}$ in terms of $t$ the total number of valence electrons and $n$, the number of heavy atoms:[28-32,65]

$$
B=4 n-t / 2 \text { and } L p=t-4 n
$$

These relationships make the following very important point: each time the total valence electron count $\mathbf{t}$ is reduced by two then an additional covalent bond is formed and two lone pairs are lost, i.e. $\Delta \mathbf{B}=-\Delta \mathbf{L} \mathbf{p} / 2$. Fig. 9 illustrates this relationship for a series containing four heavy atoms and $32-16$ valence electrons.

The Lewis covalent bond notation and simpler quantum mechanical calculations more often than not satisfactorily define the presence or absence of bonds in molecules, and suggest that as the multiplicity of a bond increases the bond will become stronger, but it fails to assess the relative strengths of bonds with the same multiplicity. For example, $\mathrm{N}_{2} \mathrm{O}_{2}$ has in the solid state (at low temperatures) the structure shown in Fig. 8, but the N-N bond is rather weak and consequently under normal laboratory conditions NO is a gas which reacts readily with dioxygen in the air to give the deep brown gas $\mathrm{NO}_{2}$. Incidentally, an isomer for $\mathrm{N}_{2} \mathrm{O}_{2}$ has also been identified with an ONON sequence. [25] The advent of computer programmes which are able to do accurate quantum mechanical calculations on reasonable sized molecules and are widely available has lessened the need to use thermodynamic data to estimate the relative strengths of bonds in molecules.

Fig. 9 summarizes the implications for the Periodic Table of the valence equations above. On the right hand side of Fig. 9 four non-bonded $\mathrm{Ne}$ atoms are shown and they represent the starting
Fig. 8. Examples of inorganic molecules with four atoms which are isoelectronic, but not isostructural. They have a total of 22 valence electrons; they are all associated with 5 bonds (B) and 6 lone pairs (Lp) and belong to 7 distinct structural types. In this Figure those molecules and ions, which are isoelectronic are shown in red and the green structures are valence isoelectronic. For each structure, the number of bonds (b) and lone pairs (Ip) associated with each atom are given in the correct sequence. These examples were taken from refs [25-28] and [73].
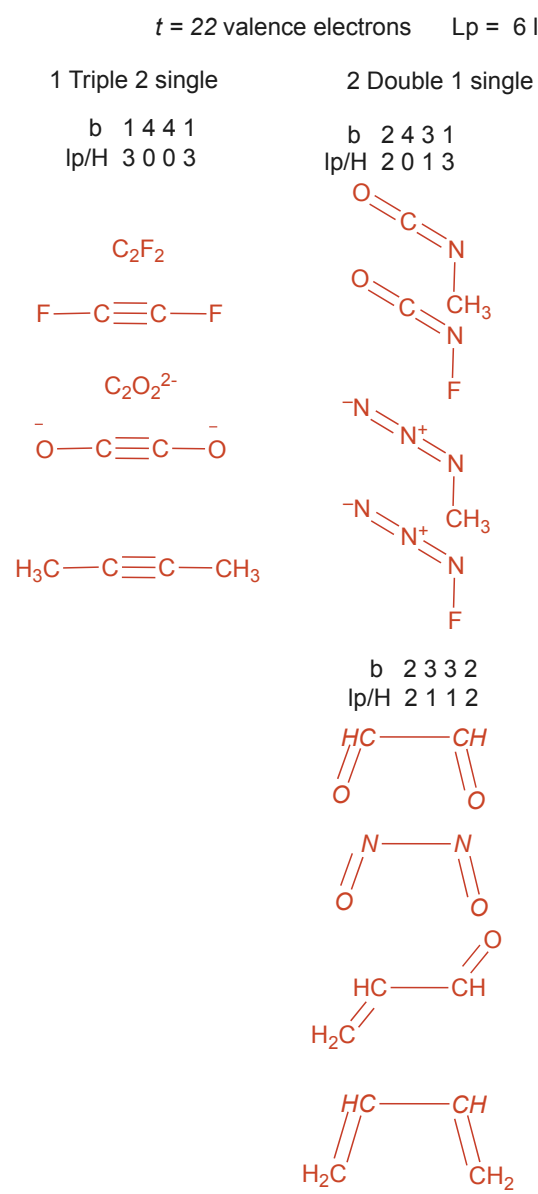

$B=5$ bonds

1 Double 3 single

b 2422

Ip/H 2022
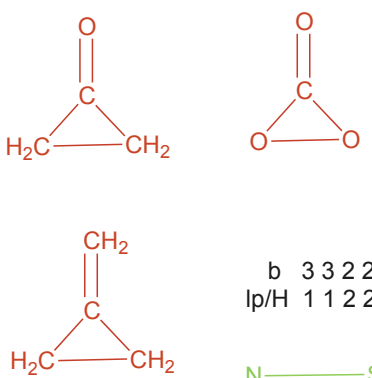

b 3313

Ip/H 1131

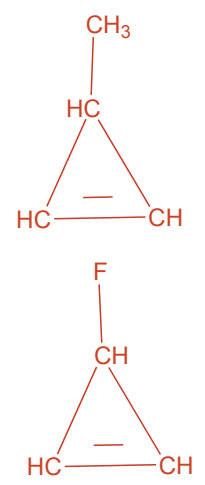

b 3322

Ip/H 11122
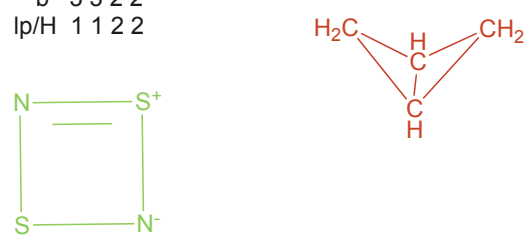

b 3322

Ip/H 1122

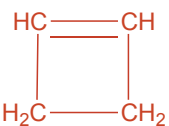


point of the analysis since in total they have 32 valence electrons, i.e. 16 lone pairs and form no $\mathrm{Ne}-\mathrm{Ne}$ covalent bonds, i.e. $\mathbf{B}=0$ and $\mathbf{L p}=16$. As we progress towards the left two lone pairs are replaced by a single covalent bond each time the total electron count, $\mathbf{t}$, is reduced by 2 (i.e. $\Delta \mathbf{B}=-\Delta \mathbf{L p} / 2$ ). This is a direct consequence of the Lewis description of the covalent bond and the octet rule. ${ }^{[28-33,66]}$ It documents how the atoms form an increasing number of bonds as their number of valence electrons diminishes. The Lewis description does not discriminate between forming $\mathbf{B}$ single bonds or single and multiple bonds which add up to a total of $\mathbf{B}$. Subsequent thermodynamic measurements have shown that multiple bonds for the first long row of elements are particularly strong and therefore the majority of molecules with multiple bonds in Fig. 9 contain these elements.

The trend in increased covalent bond formation continues until $\mathbf{t}=16$ when each atom has zero lone pairs and four bonds are formed between the nearest atoms in an infinite structure based on tetrahedra, e.g. diamond and $\mathrm{ZnS}$, or a two-dimensional sheet of hexagons with alternant atoms having double bonds, such as that observed in graphite and isoelectronic BN. ${ }^{[11]}$ The important general point that Fig. 9 makes is that as one progresses to the left of the Periodic Table the number of lone pairs diminishes in order to create covalent bonds which enable the electron density to be shared amongst the maximum number of atoms. Fig. 9 also connects to the discussion in Section 5 and provides a basis for the total electron counts in the classes described. Specifically, rings and chains of atoms have $6 n$ and $6 n+2$ valence electrons respectively, and three-connected polyhedral molecules have $5 \mathrm{n}$ valence electrons. Furthermore, it suggests that the formation of multiple bonds reduces these electron counts by 2 since a pair of lone pairs is lost in converting a single into a double bond.

The important point to note from the organization of structural data in Figs 8 and 9 is that isoelectronic molecules need not be isostructural. The permutational possibilities consistent with the valency equations permit the generation of alternative structures which conform to the octet rule and also are consistent with the characteristic valencies of the atoms, i.e. group 16 atoms having a propensity to form ring compounds with 6 n valence electrons, which is consistent with their common valency of 2; and group 15 atoms have a common valency of 3 and favour three-connected polyhedral molecules especially for the heavier elements.

The examples in Fig. 9 may be extended to molecules with fewer than 16 electrons or more than 26, but in these cases $\mathbf{B}$ no longer represents the number of two-electron bonds in the Lewis sense, but the number of electrons in more delocalized bonds. For example, $\mathrm{ClF}_{3}$ has $\mathbf{t}=28$ electrons and the equations suggest that $\mathbf{B}=2$ and $\mathbf{L p}=12$; but since there are three fluorine atoms bonded to $\mathrm{Cl}$ then multi-centred delocalized bonds are required and generally the bonding in $\mathrm{ClF}_{3}$ is described in terms of a single Lewis bond and a three-centre four-electron bond. This also applies to the other inert gas compounds in Table 5. Similarly, tetrahedral $\mathrm{Li}_{4}{ }^{2+}$ has $\mathbf{B}=1$ and $\mathbf{L p}=0$ and the bonding electron pair is represented by a delocalized multicentred two-electron bond based on the $2 \mathrm{~s}$ orbitals of the lithium atoms. ${ }^{[66]}$

\section{Steric Effects}

The steric effects of substituents have been referred to several times above. The use of sterically demanding ligands has proved to be a dominant feature of both main group and transition metal chemistry in recent decades. Attempts to prepare valence isoelectronic analogues of ethene and ethyne have used steric strategies since R groups which are very bulky diminish the possibility of forming chains and rings. The resultant Group 14 molecules $\mathrm{E}_{2} \mathrm{R}_{4}$ $\left(\mathrm{E}=\mathrm{C}, \mathrm{Si}, \mathrm{Ge}, \mathrm{Sn}\right.$ and $\mathrm{Pb}$, where $\mathrm{R}={ }^{\mathrm{t}} \mathrm{Bu}$, or $\left.\mathrm{C}\left(\mathrm{SiMe}_{3}\right)_{3}\right)$ would be expected to have planar structures analogous to ethene, $\mathrm{C}_{2} \mathrm{H}_{4}$. The molecular structures of these compounds in the solid state have shown that they become less planar and more trans-folded as the group is descended. Taken together the data suggest that the E-E bonds become progressively longer and weaker, and dissociate more readily in solution and the gas phase to give $\mathrm{ER}_{2}$ carbene analogues. The heavier examples are better represented as a pair of weakly interacting carbenes, rather than ethene analogues.

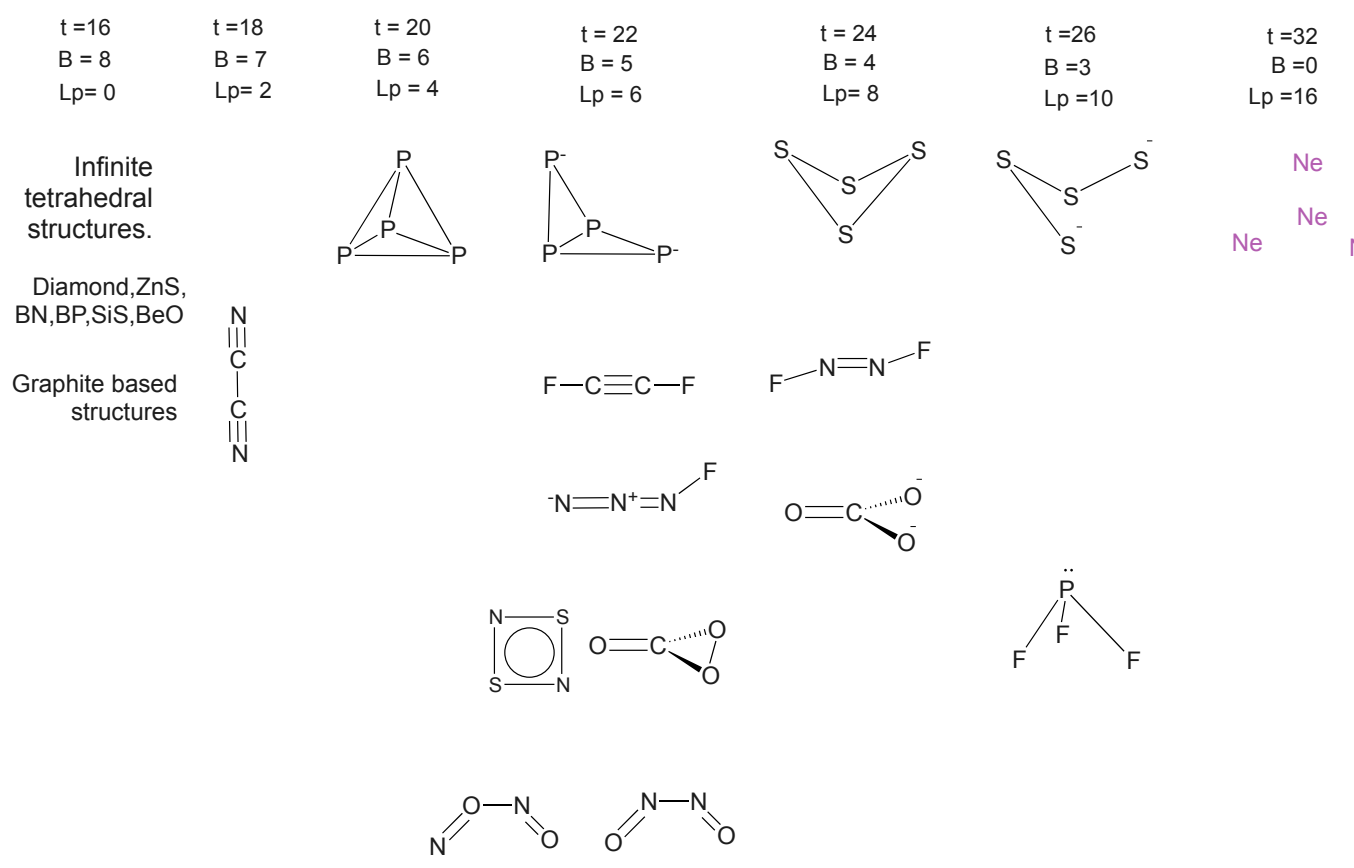

Fig. 9. Illustrations of the bond and lone pair equations for a series of molecules and ions with 4 atoms. Four non-bonded $\mathrm{Ne}$ atoms are shown on the right-hand side and no covalent bonds between them are permitted by the octet rule. Each column represents isoelectronic molecules or ions. 
The analogues of ethyne have also been shown to have non-linear structures. Both of these examples highlight the limitations of oversimplifying the inter-relationships in groups of molecules and focusing attention unduly on the inorganic core. A combination of steric and electronic effects has been used to stabilize carbenes to such an extent that they may be used as extensively as tertiary phosphines in organometallic and catalytic chemistry. ${ }^{[67-74]}$

\section{Conclusions}

Lewis and Kossel's models for understanding the bonding in chemical compounds are based on the octet rule and they have had an important impact on the development of inorganic chemistry during the last century. Their description of ionic and covalent bonds strengthened the descriptions of the Periodic Table provided by Mendeleev and Lothar Meyer and underlined the importance of valency as an important parameter for the Periodic Table. In subsequent years the Lewis-Kossel bonding models were reinterpreted within the framework of the newly developed quantum mechanics. The quantum mechanical description of the electronic states of polyelectronic atoms provided a rationalization of the structure of the Periodic Table and it replaced the localized two-electron covalent bond proposed by Lewis with one which stressed the different types of bonds which may result from the wave picture of the atom. It was also simplified and presented a pictorial methodology for discussing chemical bonding issues which chemists now use very widely to communicate ideas concerning structure and chemical reactivity.

Lewis and Kossel's description of the bonding in ionic compounds depended on isoelectronic relationships with the inert gases for the constituent anions and cations. This was later extended to isoelectronic relationships for ions which have completed sub-shells rather than full shells. Langmuir's extension of the isoelectronic principal to molecular compounds has also proved to be very significant, particularly in the last half century, when molecular orbital descriptions of the bonding became be more commonly used. Langmuir's ideas have been developed into a unifying principle and are applicable to a wide range of inorganic molecules. In this review we have demonstrated how they interrelate a wide range of cyclic molecules, three-connected and deltahedral molecules of the main group elements and shown how their geometries and electron counts relate to the Periodic Table. The review also stresses the limitations of the isoelectronic relationships and shows that there may be several molecules which are isoelectronic but not isostructural. These alternative molecular structures reflect the different ways in which the same total number of bonds and lone pairs may be distributed in the molecule. These relationships may be extended to transition metal compounds and compounds which contain transition metals and main group atoms using the isolobal principal developed previously and widely used by many chemists. ${ }^{[75]}$

Exceptions to these generalisations are being explored using modern density function molecular orbital calculations which provide a deeper understanding of the factors which are responsible for the observed geometric preferences. Developments in artificial intelligence and the ability to analyse large data sets will in future augment the synthetic chemists' ability to suggest new classes of compounds which challenge our current theories and produce new compounds with interesting and useful chemical properties. ${ }^{[76]}$

Received: January 25, 2019

[1] E. R. Scerri, 'The Periodic Table', Oxford University Press, Oxford, UK, 2007. Popular accounts celebrating the $150^{\text {th }}$ Anniversary of the Periodic Table have already appeared in: Chemistry World January 2019 and Chemical and Engineering News, 7th January 2019.

[2] A. I. Ihde, 'The Development of Modern Chemistry', Harper Row, New York, USA, 1970.
[3] C. A. Russell, 'The History of Valency', Leicester University Press, Leicester, UK, 1971

[4] T. Moeller, 'Inorganic Chemistry - An Advanced Textbook', John Wiley and Sons, New York, 1952, pp 214-215. This book provides one of the later references to Langmuir's use of isostere, but mainly as a historical aside.

[5] F. A. Cotton, G. Wilkinson, 'Advanced Inorganic Chemistry', J. Wiley and Sons, New York, 1962.

[6] B. Moody, 'Comparative Inorganic Chemistry', 1st Ed., 1965, 3rd Ed., Edward Arnold, London, UK. 1991, p 61.

[7] C. E. Housecroft, A. G. Sharpe, 'Inorganic Chemistry', 4th Ed., Pearson, Harlow, UK, 2012.

[8] P. W. Atkins, M. T. Weller, J. P. Rourke, T. I. Overton, F. A. Armstrong, 'Shriver and Atkins Inorganic Chemistry', 5th Ed., Oxford University Press, Oxford, UK, 2014.

[9] J. F. Huheey, E. A. Keitler, R. L. Keitler, 'Inorganic Chemistry: Principles of Structure and Reactivity', 4th Ed., Harper Collins, New York, 1993, p 640.

[10] J. C. Kotz, P. Treichel, 'Chemistry and Chemical Reactivity', 4th Ed., Saunders College Publishing, New York, USA, 1999, p 390.

[11] U. Müller, 'Inorganic Structural Chemistry', 5th Ed., John Wiley and Sons, Chichester, UK, 2007.

[12] D. M. P. Mingos, 'Essential Trends in Inorganic Chemistry', Oxford University Press, Oxford, UK, 1998

[13] G. W. Rayner-Canham, T. L. Overton, 'Descriptive Inorganic Chemistry', 4th Ed., W.H. Freeman Publishing Co., New York, USA, 2006, p 30.

[14] N. N. Greenwood, A. Earnshaw, 'Chemistry of the Elements', 2nd Ed. Butterworth-Heinemann, Oxford, 1997.

[15] G. N. Lewis, J. Am. Chem. Soc. 1916, 38, 762.

[16] G. N. Lewis, Proc. Nat. Acad. 1916, 2, 588.

[17] G. N. Lewis, 'Valence and the Structures of Atoms and Molecules', The Chemical Catalog. Company, New York, USA, 1923.

[18] W. Kossel, Ann. Phys. 1916, 49, 229.

[19] D. M. P. Mingos, Struct. Bond. 2016, 169, 1

[20] J. M. Thomas, Angew. Chem. Int. Ed. 2004, 43, 6418.

[21] A. R. West, 'Basic Solid State Chemistry, Second Edition', John Wiley and Sons, Chichester, UK, 1999

[22] P. W. Atkins, 'Molecular Quantum Mechanics, An Intorduction to Quantum Chemistry, Parts I and II', Oxford University Press, Oxford, UK, 1970.

[23] a) N. V. Sidgwick, 'The Electronic Theory of Valency', Clarendon Press, Oxford, UK, 1960; b) A. H. Sommer, Nature 1943, 152, 215; c) U. Zachwieja, Z. Anorg. Allg.Chem. 1993, 619, 1095.

[24] J. L. Dye, Angew. Chem. Int. Ed. Engl. 1979, 18, 587.

[25] A. Halland, 'Molecules and Models', Oxford University Press, Oxford, UK, 2008.

[26] A. Halland, Struct. Bond. 2016, 169, 1.

[27] W. B. Jensen, J. Chem. Educ. 1984, 61, 91.

[28] I. Langmuir, J. Am. Chem. Soc. 1919, 41, 868.

[29] I. Langmuir, J. Am. Chem. Soc. 1919, 42, 274.

[30] I. Langmuir, Proc. Nat. Acad. Sci. 1919, 5, 252.

[31] I. Langmuir, Science 1921, 54, 59.

[32] I. Langmuir, Nature 1920, 105, 261.

[33] I. Langmuir, J. Am. Chem. Soc. 1919, 41, 1543.

[34] L. Pauling, 'The Nature of the Chemical Bond', 1st Ed., Cornell University Press, USA, 1938.

[35] a) W. B. Jensen, J. Chem. Educ. 2005, 82, 28; b) G. D. Parkin, J. Chem. Educ. 2006, 83, 791.

[36] H. L. Bradlow, S. Vander Werf, J. Kleiberg, J. Chem. Educ. 1947, 24, 433.

[37] G. W. Rayner-Canham, Found. Chem. 2009, 11, 123.

[38] a) R. McWeeny, 'Coulson's Valence', 3rd Ed., Oxford University Press, Oxford, UK, 1979; b) C. A. Coulson, 'Valence', 2nd Ed., Oxford University Press, Oxford, 1961

[39] M. J. S. Dewar, 'The molecular orbital theory of organic chemistry', McGraw-Hill \& Co, New York, 1969; M. J. S. Dewar, 'The electronic theory of organic chemistry', Oxford University Press, Oxford, 1949.

[40] R. J. Martinie, J. J. Bultema, M. N. van der Wal, B. J. Burkhart, D. A. van der Griend, R. L. de Kock, J. Chem. Educ. 2011, 88, 1094.

[41] P. L. Timms, Adv. Inorg. Chem. Radiochem. 1972, 143.

[42] a) V. Dragoslav, S. Aldridge, Angew. Chem. 2009, 121, 3723; b) V. Dragoslav, S. Aldridge, Chem. Sci. 2011, $2,601$.

[43] E. Whittle, D. A. Dows, G. C. Pimentel, J. Chem. Phys. 1954, 22, 1943.

[44] I. R. Dunkin, 'Matrix-Isolation Techniques - A Practical Approach', Oxford University Press, Oxford, UK, 1998.

[45] D. F. Shriver, 'Handling of Air Sensitive Compounds', McGraw-Hill, New York, 1969.

[46] R. G. Pearson, 'Chemical Hardness: applications from molecules to solids' Springer, Heidelberg, Germany, 1997.

[47] S. Ahrland, J. Chatt, N. R. Davies, Quart. Rev. 1958, 12, 265.

[48] N. Bartlett, Proc. Chem. Soc. (London) 1962, 218.

[49] J. H. Holloway, Noble-Gas Chemistry. London: Methuen., 1968.

[50] K. Seppelt, Acc. Chem. Res. 1979, 12, 211.

[51] J. D. Woollins, 'Non-Metal Rings, Cages and Clusters', John Wiley and Sons, Chichester, 1988. 
[52] G. Mehta, S. Padma, in 'Carbocyclic Cage Compounds', Eds. E. Osawa, O. Yonemitsu, Weinheim, Germany, 1992.

[53] M. J. McGlinchey, H. Hopf, Beilstein J Org Chem. 2011, 7, 222.

[54] R. E. Williams, Inorg Chem. 1971, 10, 210.

[55] K. Wade, J. Chem. Soc. Chem. Commun. 1971, 792.

[56] D. M. P. Mingos, Nature Phys. Sci. 1971, 236, 99.

[57] T. Fässler, Struct. Bond. 2011, 139, 1.

[58] K. Wade, 'Electron Deficient Compounds', Thomas Nelson and Sons, London, UK, 1971.

[59] B. M. Gimarc, 'Molecular Structure and Bonding', Academic Press, New York, USA, 1979.

[60] a) H. C. Longuet-Higgins, R. P. Bell, J. Chem. Soc. 1943, 250; b) H.C. Longuet-Higgins, M. de V Roberts, Proc. Roy. Soc. 1955, 230, 110.

[61] R. W. Rudolph, Acc. Chem. Res. 1976, 9, 446.

[62] D. M. P. Mingos, R. L. Johnston, Struct. Bond. 1987, 68, 31.

[63] W. N. Lipscomb, Adv. Inorg. Radiochem. 1959, 1, 118.
[64] W. N. Lipscomb, Acc. Chem. Res. 1973, 6, 257.

[65] A. J. Welch, Crystals 2017, 7, 234.

[66] D. M. P. Mingos, Struct. Bond. 2016, 169-171, 1.

[67] P. P. Power, J. Chem. Soc. Dalton Trans. 1998, 2939.

[68] M. Weldenbruch, Eur. J. Inorg. Chem. 1999, 373.

[69] H. Grützmacher, T. F. Fässler, Chem. Eur., J. 2000, 6, 2317.

[70] K. Kishakwa, N. Tokitoh, R. Okazaki, Chem. Lett. 1998, 239.

[71] K. Kim, G. A. Lawless, R. M. Merritt, J. M. Miller, G. G. Webb, J. Am. Chem. Soc. 1987, 109,

[72] A. J. Arduengo; R. L. Harlow, M. Kline, J. Am. Chem. Soc. 1991, 113, 361.

[73] A. J. Arduengo; H. V. R. Dias; R. L. Harlow; M. Kline, J. Am. Chem. Soc. 1992, 114, 5530.

[74] X. Bantreil, S. P. Nolan, Nature Protocols 2011, 6, 69.

[75] R. Hoffmann, Angew. Chem. Int. Ed. Engl. 1982, 21, 711.

[76] D. M. P. Mingos, Ed. 'The Chemical Bond I-II, 100 Years Old and Still Going Strong', Struct. Bond. 2016, 169-171. 